\title{
Precipitation Modulation by the Saint Lawrence River Valley in Association with Transitioning Tropical Cyclones*
}

\author{
Shawn M. Milrad, Eyad H. Atallah, and John R. Gyakum \\ Department of Atmospheric and Oceanic Sciences, McGill University, Montreal, Quebec, Canada
}

(Manuscript received 14 July 2012, in final form 22 October 2012)

\begin{abstract}
The St. Lawrence River valley (SLRV) is an important orographic feature in eastern Canada that can affect surface wind patterns and contribute to locally higher amounts of precipitation. The impact of the SLRV on precipitation distributions associated with transitioning, or transitioned, tropical cyclones that approached the region is assessed. Such cases can result in heavy precipitation during the warm season, as during the transition of Hurricane Ike (2008). Thirty-eight tropical cyclones tracked within $500 \mathrm{~km}$ of the SLRV from 1979 to 2011. Utilizing the National Centers for Environmental Prediction (NCEP) North American Regional Reanalysis (NARR), 19 of the 38 cases (group A) had large values of ageostrophic frontogenesis within and parallel to the SLRV, in a region of northeasterly surface winds associated with pressure-driven wind channeling. Using composite and case analyses, results show that the heaviest precipitation is often located within the SLRV, regardless of the location of large-scale forcing for ascent, and is concomitant with ageostrophic frontogenesis. The suggested physical pathway for precipitation modulation in the SLRV is as follows. Valley-induced near-surface ageostrophic frontogenesis is due to pressuredriven wind channeling as a result of the along-valley pressure gradient [typically exceeding $0.4 \mathrm{hPa}$ $(100 \mathrm{~km})^{-1}$ ] established by the approaching cyclone. Near-surface cold-air advection as a result of the northeasterly pressure-driven channeling results in a temperature inversion, similar to what is observed in cool-season wind-channeling cases. The ageostrophic frontogenesis, acting as a mesoscale ascent-focusing mechanism, helps air parcels to rise above the temperature inversion into a conditionally unstable atmosphere, which results in enhanced precipitation focused along the SLRV.
\end{abstract}

\section{Introduction}

\section{a. Motivation}

The St. Lawrence River valley (SLRV) is an important orographic feature in eastern Canada that has been previously shown to have impacts on the observed weather in communities located along the valley (e.g., Roebber and Gyakum 2003; Razy et al. 2012). One pertinent example was the 1998 Ice Storm that resulted in substantial damage in the SLRV [\$3 billion U.S. dollars in

\footnotetext{
* Supplemental information related to this paper is available at the Journals Online website: http://dx.doi.org/10.1175/WAF-D-1200071.s1.

Corresponding author address: Shawn M. Milrad, Dept. of Atmospheric and Oceanic Sciences, McGill University, 805 Sherbrooke St. W., Montreal QC H3A 2K6, Canada.

E-mail: shawn.milrad@gmail.com
}

damage; NCDC (2010)]. Roebber and Gyakum (2003) found that during the 1998 ice storm, the orography of the SLRV contributed substantially to higher amounts of precipitation (hereafter enhanced precipitation) within the SLRV through ageostrophic frontogenesis.

The SLRV is oriented southwest to northeast, from the eastern end of Lake Ontario to the Gulf of St. Lawrence (Fig. 1a; Google Maps 2011). Two major Canadian cities (Montreal and Quebec City) are located within the SLRV, which is home to the majority of the population in the province of Quebec. Several mountain chains surround the SLRV: the Laurentian Mountains to the north, and the Adirondack, Green, and White Mountains to the south (Figs. 1a,b). All four mountain chains (the Adirondacks, in particular) have individual peaks above $800 \mathrm{~m}$ (Fig. 1b) (Amante and Eakins 2009). Montreal, Quebec (CYUL), is located at the confluence of three river valleys: the SLRV, which runs directly through CYUL, the Ottawa River valley to the west, and the Lake Champlain valley to the south (Fig. 1b), all of 


\section{a)}

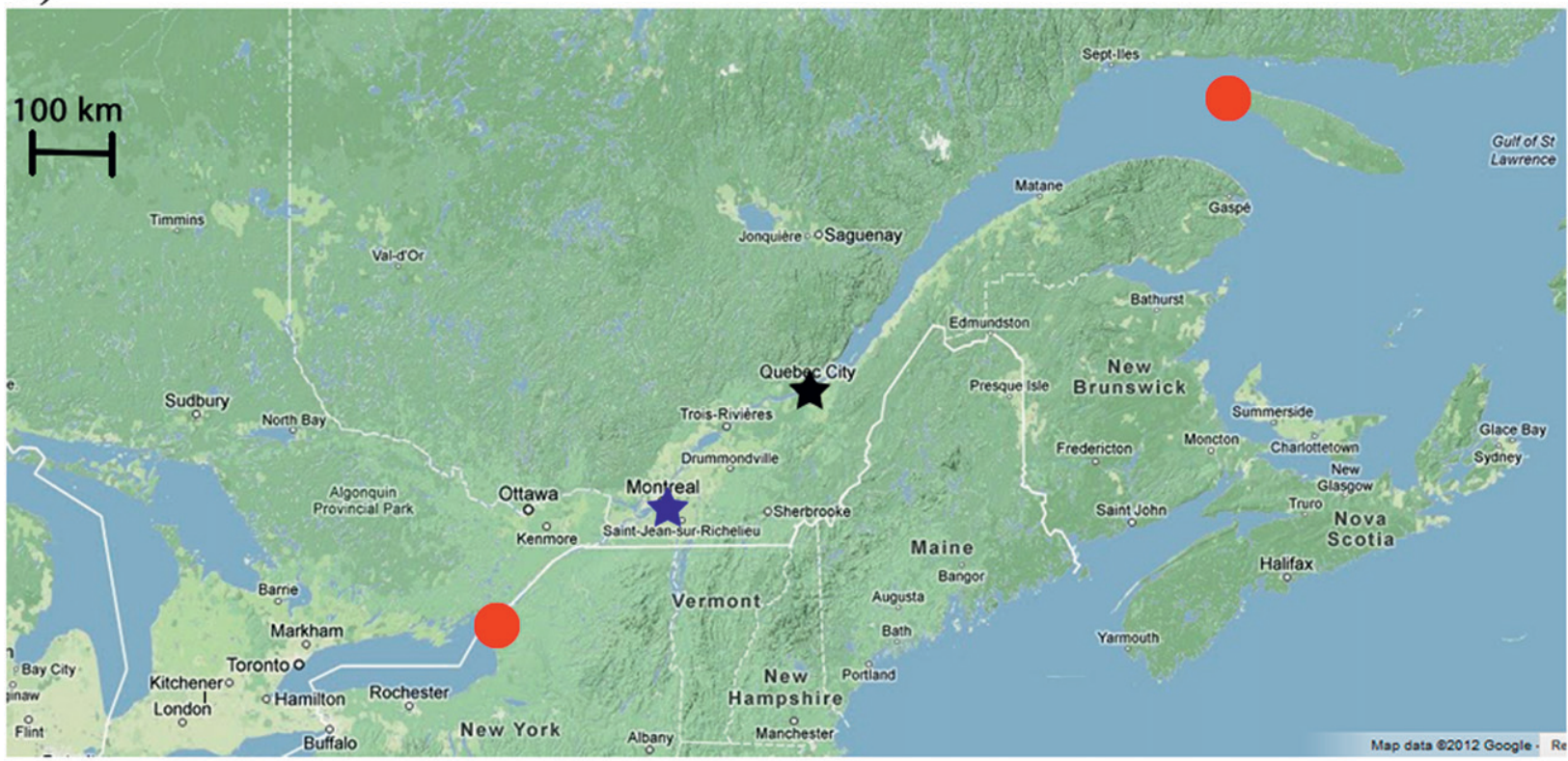

b)

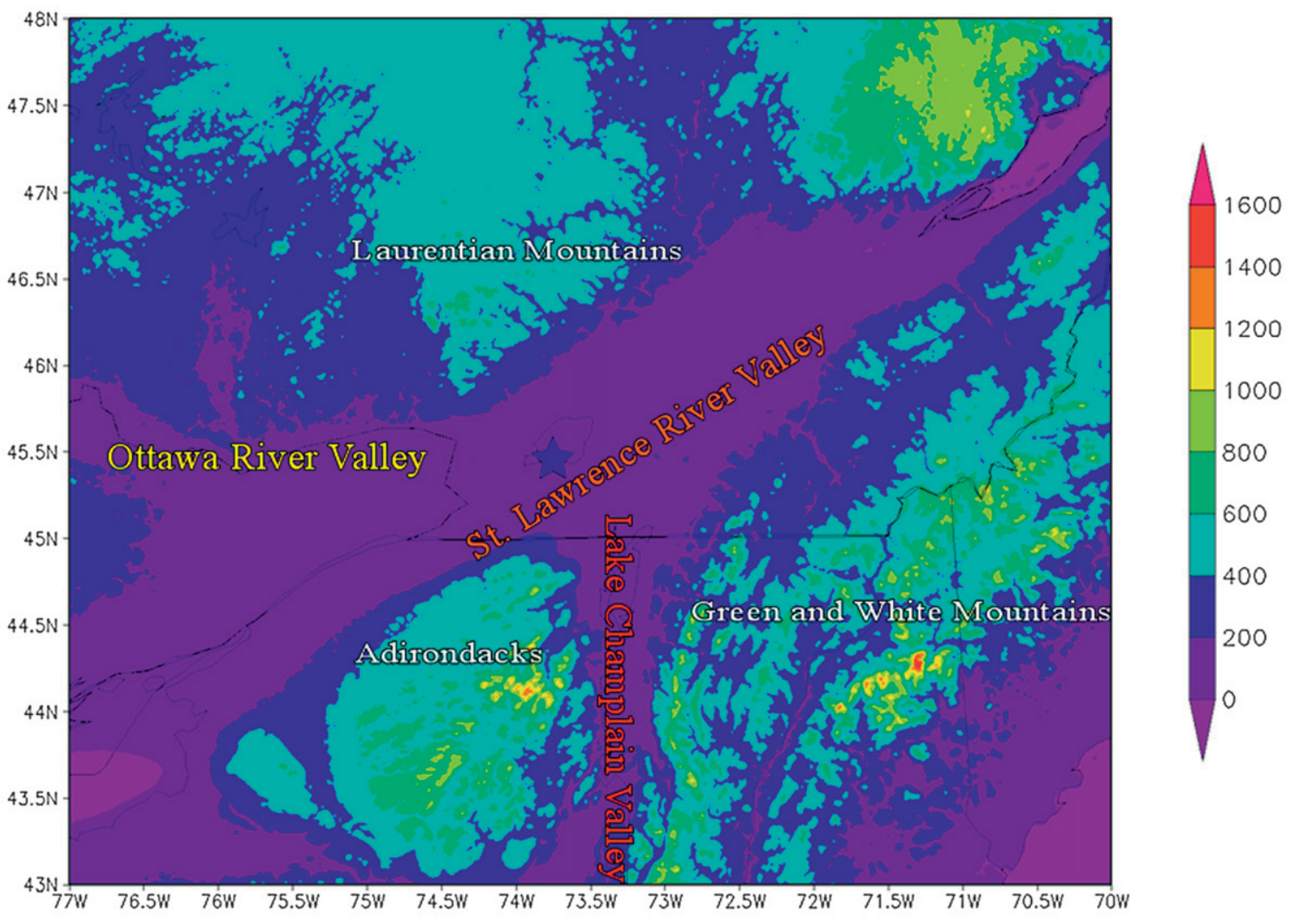

GrADS: COLA/IGES

$2010-04-07-12: 11$

FIG. 1. Topography of (a) the northeast-southwest-oriented SLRV and surrounding areas (Google Maps 2011) and (b) elevation in the vicinity of Montreal, plotted using the ETOP1 Global Relief Model (Amante and Eakins 2009). In (a), Quebec City's Jean Lesage International Airport (CYQB) is marked with a black star and the approximate endpoints of the SLRV are marked by red ovals. In both (a) and (b), Montreal's Trudeau International Airport (CYUL) is marked with a blue star. 
which can impact surface wind regimes (Carrera et al. 2009; Razy et al. 2012). The width of the SLRV varies over its length, ranging from as narrow as $3 \mathrm{~km}$ in some locations to $90 \mathrm{~km}$ around CYUL. The average width of the SLRV is approximately $50 \mathrm{~km}$ (Carrera et al. 2009; Razy et al. 2012).

Earlier work has demonstrated a climatological northeast-southwest bimodality in observed winds at various locations throughout the SLRV that correspond to the orientation of the valley (Powe 1969; Cohn et al. 1996; Slonosky 2003; Carrera et al. 2009; Razy et al. 2012) and can subsequently have an impact on the observed weather within the SLRV (Roebber and Gyakum 2003; Razy et al. 2012). The bimodality is related to certain types of forcing mechanisms (sometimes referred to as wind channeling) within the valley (Carrera et al. 2009; Razy et al. 2012). There are four forcing mechanisms for valley winds (Whiteman and Doran 1993): thermal forcing, downward momentum transport, forced channeling, and pressure-driven channeling. For a more complete conceptual overview of the various forcing mechanisms for valley winds, we suggest Whiteman and Doran (1993), Kossmann and Sturman (2003), Carrera et al. (2009), and Razy et al. (2012).

We primarily focus on pressure-driven wind channeling, in which the wind, owing to the synoptic-scale pressure gradient from one end of the valley to the other, blows along the axis of the valley toward lower pressure regardless of the direction of the geostrophic wind (Gross and Wippermann 1987; Carrera et al. 2009; Razy et al. 2012). Previous research has shown that pressure-driven channeling is often the dominant channeling mechanism in wide and shallow valleys such as the SLRV and the Rhine valley in Germany (Whiteman and Doran 1993; Bergstrom and Juuso 2006; Carrera et al. 2009; Razy et al. 2012). Weber and Kaufmann (1998) and Razy et al. (2012) suggested that the dominance of pressure-driven channeling in broad and shallow valleys is likely due to the fact that wide valleys tend to be long valleys, thus facilitating the establishment of a synoptic-scale pressure gradient.

Several studies (Roebber and Gyakum 2003; Razy et al. 2012; Ressler et al. 2012) have noted that orographic effects combined with synoptic-scale forcing for ascent can lead to enhanced and/or prolonged precipitation events within the SLRV. Roebber and Gyakum (2003) showed that with lower pressure located at the southwestern end of the SLRV, northeasterly pressure-driven channeling along the long axis of the SLRV (Fig. 2, red line), in combination with south-southeasterly geostrophic winds, produced ageostrophic frontogenesis in the SLRV during the 1998 Ice Storm. The ageostrophic frontogenesis acted as a

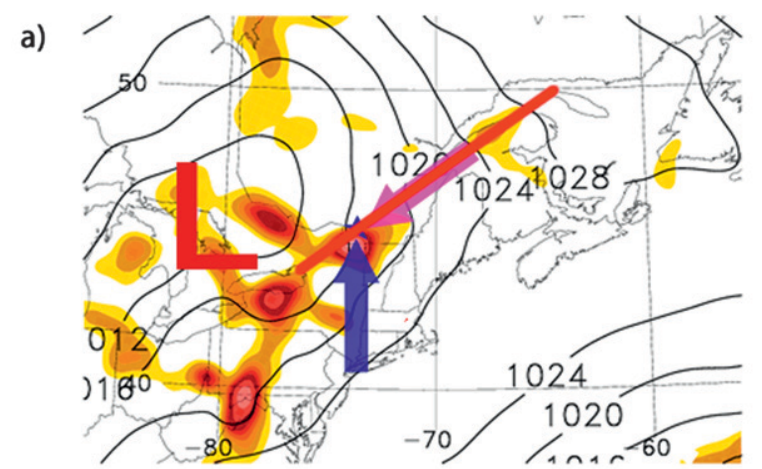

b)
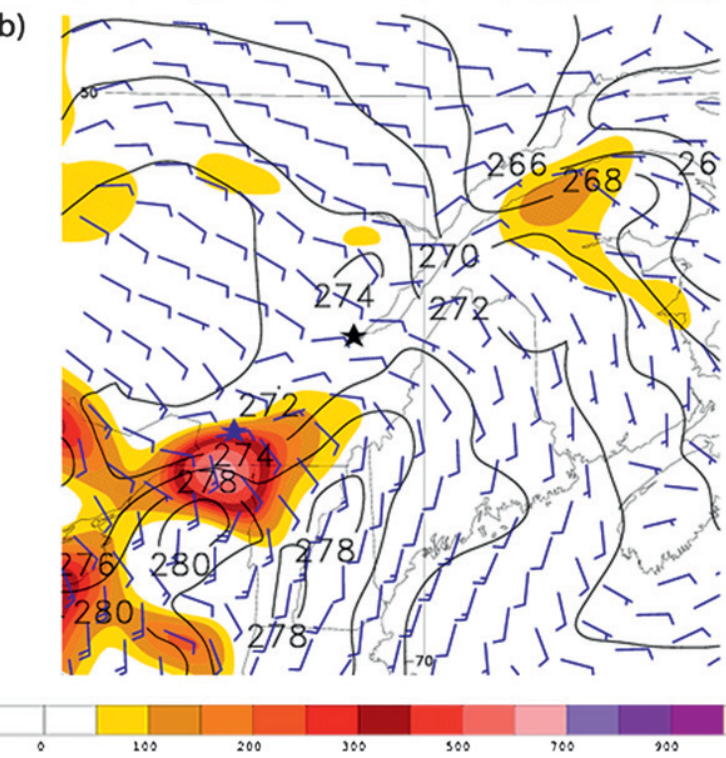

100

900

FIG. 2. Case examples (1500 UTC 25 Feb 2002) in the SLRV of (a) NARR 30-m frontogenesis [shaded, $\mathrm{K}(100 \mathrm{~km})^{-1}(3 \mathrm{~h})^{-1}$ ] and SLP (hPa, solid contours) and (b) NARR 30-m frontogenesis [shaded, K $(100 \mathrm{~km})^{-1}(3 \mathrm{~h})^{-1}$ ], 30-m wind (kt, barbs) and 30-m potential temperature ( $\mathrm{K}$, solid contours). Schematic in (a) indicates observed valley-channeled surface wind direction (pink arrow) and approximate geostrophic wind direction (blue arrow), while the long axis of the SLRV is approximated by the red line. For reference, CYUL is located at the junction of the two arrows in (a) and with a black star in (b). [Adapted from Razy et al. (2012).]

mesoscale ascent-focusing mechanism that contributed to large freezing-rain accumulations (Roebber and Gyakum 2003).

Figures $2 \mathrm{a}, \mathrm{b}$ show a representative case from a composite study of 20 cold-season cyclones tracking through the SLRV from 1979 to 2002, which revealed valleyinduced frontogenesis in the SLRV (Razy 2010). In Fig. 2a, a cyclone is located to the west of the SLRV, with a pressure gradient oriented northeast-southwest along the SLRV. The near-surface $(30 \mathrm{~m})$ winds are northeasterly within the SLRV, but generally southeasterly outside the SLRV (Fig. 2b). These winds result in a tightening of the potential temperature gradient in the 
SLRV (Fig. 2b) and are, thus, conducive to ageostrophic frontogenesis (Figs. 2a,b).

\section{b. Transitioning tropical cyclones}

Hart and Evans (2001) found that 50\% of landfalling tropical cyclones in the North Atlantic basin have undergone extratropical transition (ET) at some point in their life cycle. Many of these storms bring heavy rain and high winds to areas in eastern North America (Hart and Evans 2001; Jones et al. 2003).

Most early literature on ET focused on case studies that brought about major flooding in the eastern United States and Canada, such as Hurricane Hazel in 1954 (Palmén 1958; Matano 1958; Weese 2003) and Tropical Storm Agnes in 1972 (Carr and Bosart 1978; DiMego and Bosart 1982a,b; Bosart and Dean 1991). For a broad overview of the many issues regarding ET dynamics, we suggest the summary article of Jones et al. (2003) and the introduction section of Milrad et al. (2009).

Studies regarding the impacts of ET on Canada are relatively sparse, although several case studies examined the ET dynamics of Hurricanes Danielle (1998) and Earl (1998) (McTaggart-Cowan et al. 2003, 2004; Ma et al. 2003), Hurricane Michael (2000) (Fogarty 2002; Abraham et al. 2002), and Juan (2003) (McTaggartCowan et al. 2006a,b). Milrad et al. (2009) assembled a climatology of transitioning storms that specifically impacted Canada, identifying 40 cases from 1979 to 2005.

Atallah and Bosart (2003) and Atallah et al. (2007) found that storms that had undergone or were undergoing ET (and had thus interacted with an upstream midlatitude trough) exhibited left-of-track precipitation distributions, while storms that did not undergo ET had precipitation distributions to the right of track. Milrad et al. (2009) came to similar conclusions for eastern Canada. Whether the majority of precipitation occurs left or right of track has important forecasting implications, as evidenced during the transition of Hurricane Floyd (Atallah and Bosart 2003; Colle 2003). Moreover, various case studies have shown that precipitation associated with ET or the remnants of tropical cyclones can result in extreme precipitation events in eastern North America (DiMego and Bosart 1982a,b; Bosart and Lackmann 1995; Atallah and Bosart 2003; Atallah et al. 2007; Milrad et al. 2009). Occasionally, extreme precipitation events can still occur when the transitioning storm is not very intense, as was the case with the remnants of Hurricanes Camille (1969) and David (1979) (Chien and Smith 1977; Bosart and Lackmann 1995; Atallah et al. 2007). Many of the cases examined by Milrad et al. (2009) were associated with heavy precipitation events in Canada, particularly those with leftof-track precipitation signatures.
One mesoscale mechanism that has been found to result in locally enhanced precipitation is frontogenesis. Bosart et al. (1972) and Bosart (1975) showed that coastal frontogenesis along the New England coast is often associated with enhanced precipitation during cool-season cyclones. Novak et al. (2004, 2006) showed that strong deep-layer frontogenesis and weak static stability were important factors in the formations of heavy mesoscale precipitation bands within cold-season northeastern U.S. cyclones. Milrad et al. (2010) showed that frontogenesis was a main mechanism for ascent in a subset of extreme precipitation events at St. John's, Newfoundland. However, very little documentation exists in the literature regarding the impact of frontogenesis on precipitation associated with transitioning tropical cyclones.

In 2008, the cyclone resulting from the extratropical transition of Hurricane Ike (2008) tracked near the SLRV, depositing large amounts of precipitation (Canadian Hurricane Centre 2008) over the length of the valley (Fig. 3a). From 0600 to 1200 UTC 15 September, the heaviest precipitation was located to the south of Ike's path (Fig. 3a), or right of center (Atallah et al. 2007; Milrad et al. 2009). However, at later times in the northeastern SLRV, the heaviest precipitation was located to the north of Ike's track, or left of center (Fig. 3a). Given that the storm (according to the National Hurricane Center's best-track dataset) had become extratropical well before 0600 UTC 15 September, one would typically expect the heaviest precipitation to be left of center (Atallah et al. 2007; Milrad et al. 2009). However, the heaviest precipitation amounts lined up nearly perfectly with the axis of the SLRV, regardless of whether the heaviest precipitation was located to the north or south of Ike's circulation center (Fig. 3a). This is suggestive of an association between the SLRV itself (and its orography) and the location of heaviest precipitation.

Although objective indicators of ET have been identified (e.g., Evans and Hart 2003) and are used operationally, we do not consider whether a storm has officially been declared extratropical, similar to the methodology of Milrad et al. (2009). For reference, most (29 of 38) cases that affected the SLRV in this study officially underwent ET.

\section{c. Objectives}

The primary objectives of this paper are to

- compile a climatology of transitioning tropical cyclones that affected the SLRV from 1979 to 2011;

- identify cases that were associated with (a) nearsurface ageostrophic frontogenesis oriented parallel to the long axis of the SLRV and (b) northeasterly 


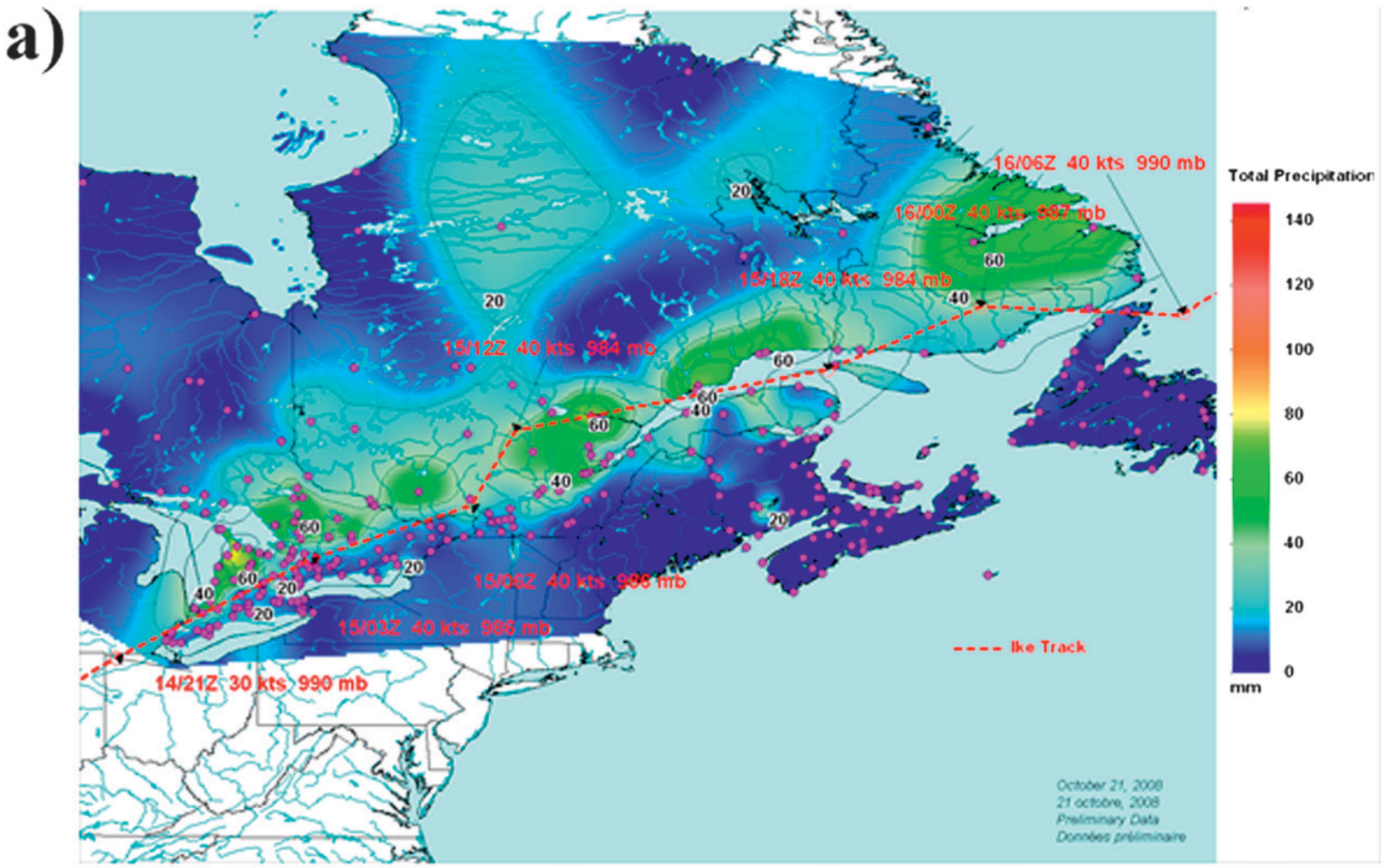

b)

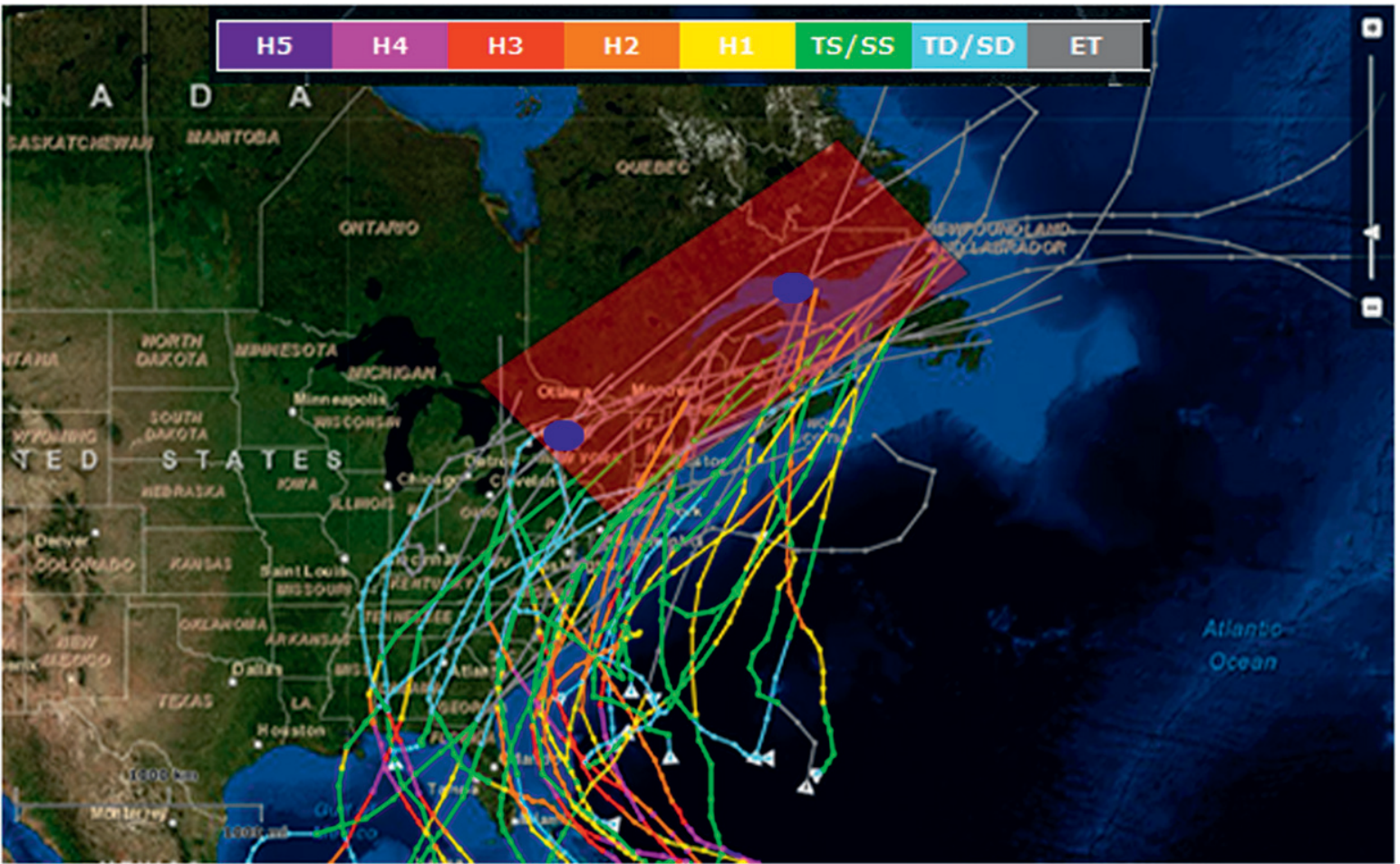

FIG. 3. Storm tracks for (a) Hurricane Ike (14-16 Sep 2008) over Canada (Canadian Hurricane Center 2011) and (b) the 38 cases (19792011) examined in this study from the NHC best-track dataset. In (a) the track of Ike is marked with a dashed red line and precipitation $(\mathrm{mm})$ is shaded using Environment Canada observed gauge data. In (b), the red box identifies the area within $500 \mathrm{~km}$ of the SLRV and gray lines indicate storms that have been classified as extratropical by NHC, while colored lines indicate storms that are still classified as tropical. Tropical cyclone intensity categories are denoted in the map legend. The approximate SLRV endpoints, previously marked in Fig. 1, are marked with blue ovals. 
(channeled) surface winds that strongly deviate from the geostrophic wind direction;

- contrast the dynamics of cases with near-surface ageostrophic frontogenesis to those of null cases;

- evaluate the association between near-surface ageostrophic frontogenesis and precipitation distributions in the vicinity of the SLRV; and

- identify a physical pathway through which valleyinduced ageostrophic frontogenesis can result in enhanced precipitation in the SLRV.

Section 2 of this paper details the data used in the study. Section 3 gives an overview of the case selection and partitioning. Section 4 presents the results of a synoptic-dynamic analysis of our cases, including an examination of the soundings. Finally, section 5 presents our conclusions as well as avenues for future work.

\section{Data}

Cases were chosen using the National Hurricane Center (NHC) best-track dataset (online at http://www. nhc.noaa.gov/pastall.shtml), and are viewed using the National Oceanic and Atmospheric Administration (NOAA) Coastal Services Center historical hurricane tracks plotter (online at http://www.csc.noaa.gov/hurricanes/). For the synoptic-dynamic analysis, we utilized the National Centers for Environmental Prediction (NCEP) North American Regional Reanalysis (NARR) dataset (Mesinger et al. 2006), which has 32-km horizontal resolution, 45 vertical layers, and 3-hourly output. The NARR has been shown to be sufficient at identifying many synoptic and mesoscale features and processes (e.g., Mesinger et al. 2006), including wind channeling in the SLRV (Carrera et al. 2009; Razy et al. 2012).

The main limitation of the NARR is the inaccuracy of the precipitation field over Canada, in which precipitation often appears to "stop" at the U.S.-Canada border (Bukovsky and Karoly 2007; West et al. 2007; Becker et al. 2009; Milrad et al. 2009). We partially compensate for this by focusing on the precipitation for a subset of cases from 2003 to 2011, for which we have gridded precipitation data from the 6-hourly Canadian Precipitation Analysis (CaPA) dataset (Mahfouf et al. 2007). The CaPA dataset has a horizontal resolution of $15 \mathrm{~km}$, and is based on the assimilation of rain gauge observations, radar data, and short-range precipitation forecasts from the Canadian Meteorological Centre's regional model. The CaPA data match up well with archived precipitation data from stations along the SLRV (not shown).

The NARR and CaPA diagnostics were produced using the General Meteorology Package (GEMPAK), version 6.2.0, which is updated from the original package devised by Koch et al. (1983).

\section{Case selection and methods used}

\section{a. Case selection}

Using NHC best-track data, we identify 38 cases of tropical cyclones from 1979 to 2011. We stipulated that these storms had to track within $500 \mathrm{~km}$ of anywhere in the SLRV (Fig. 3b) at some point. Figure 3b shows the tracks of all 38 cases, with the red parallelogram marking the area through which a storm was required to track in order to be included in this study $(500 \mathrm{~km}$ from the SLRV in any direction). The study area encompasses much of eastern Canada, with the exception of southeastern Newfoundland, as well as parts of the northeastern and Great Lakes regions of the United States.

Figure $3 \mathrm{~b}$ shows that the majority of the 38 cases tracked to the east or southeast of the SLRV, while only a few circulation centers actually moved through the SLRV. Figure $3 \mathrm{~b}$ also shows that most of the cases had already undergone ET by the time they came within $500 \mathrm{~km}$ of the SLRV. A few notable cases that remained classified as tropical systems while impacting the SLRV (Fig. 3b) were Gloria (1985), Floyd (1999) (Atallah and Bosart 2003; Colle 2003), and Juan (2003) (McTaggartCowan et al. 2006a,b).

\section{b. Case partitioning}

Roebber and Gyakum (2003) and Razy et al. (2012) suggested that ageostrophic frontogenesis occurs in the SLRV because the surface winds are channeled from high to low pressure down the valley (northeast to southwest), while surface winds outside of the SLRV are from disparate directions. Miller (1948), Keyser et al. (1988), and Bluestein (1993) defined frontogenesis as the rate of change over time of the horizontal potential temperature gradient, exhibited by

$$
F=\frac{D}{D t}\left|\nabla_{p} \theta\right|,
$$

where $F$ is the frontogenesis function and $\theta$ is potential temperature. In accordance with Eq. (1), we used the 2D frontogenesis equation in our calculations. To diagnose the ageostrophic frontogenesis, we first calculated the ageostrophic wind vector by subtracting the geostrophic wind vector calculated from NARR sea level pressure (SLP) from the NARR 30-m total wind vector. We recorded the time of maximum ageostrophic frontogenesis in the SLRV for each storm; hereafter, $t=0 \mathrm{~h}$ (Tables $1-3$ ). In the absence of ageostrophic frontogenesis in the SLRV, we took 
TABLE 1. Group A cases $(n=19)$. The subset of 10 cases where CaPA data were available (2003-11) are in boldface and are shown in Fig. 4. The locations and times listed are those of the observed maximum ageostrophic frontogenesis in the $\operatorname{SLRV}(t=0 \mathrm{~h})$

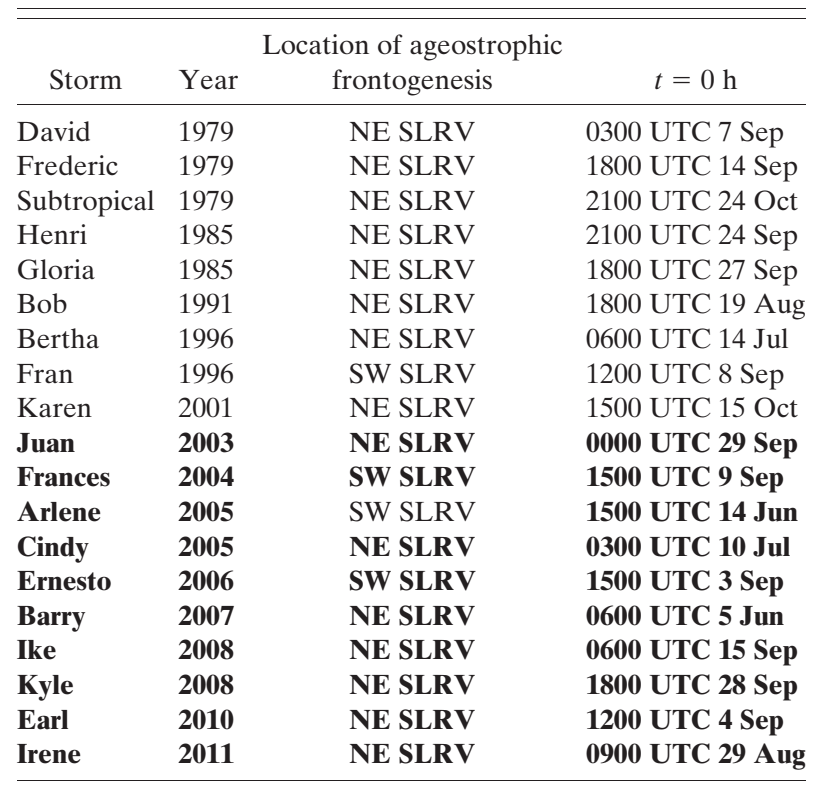

the time of the storm's closest approach to the SLRV (also $t=0 \mathrm{~h}$ ).

While not all ageostrophic frontogenesis is due to the orography of the SLRV, we can likely attribute some of it if it is oriented parallel to the long axis of the valley. To test whether the NARR is correctly identifying ageostrophic frontogenesis in the SLRV due to its high resolution being able to correctly discern the orography of the valley, all of the cases in this study were also examined using the NCEP Climate Forecast System Reanalysis (CFSR; Saha et al. 2010). The CFSR has a coarser horizontal resolution than the NARR $\left(0.5^{\circ}\right.$ latitude versus $32 \mathrm{~km}$ ). We found that the ageostrophic frontogenesis in the SLRV for the cases shown in Fig. 4 was generally not present in the CFSR (see Supplement 1 to this paper online at http://dx.doi.org/10.1175/WAF-D12-00071.s1). This finding is not limited to the derived ageostrophic frontogenesis field; the near-surface wind and potential temperature structures are also quite different between the two reanalyses (see Supplement 1).

Roebber and Gyakum (2003) and Razy et al. (2012) demonstrated that modulation of observed weather and precipitation within the SLRV occur primarily when ageostrophic frontogenesis occurs in concert with channeled northeasterly surface winds blowing toward lower pressure. As such, we only consider the impacts on precipitation distribution in cases where the ageostrophic frontogenesis is collocated with northeasterly surface winds. Synoptic-scale forcing for ascent is usually
TABLE 2. Group B cases $(n=5)$, as shown in Fig. 5 . The $t=0 \mathrm{~h}$ is defined as the time of closest approach to the SLRV.

\begin{tabular}{lll}
\hline \hline \multicolumn{1}{c}{ Storm } & Year & \multicolumn{1}{c}{$t=0 \mathrm{~h}$} \\
\hline Chris & 1988 & 0600 UTC 30 Aug \\
Josephine & 1996 & 1200 UTC 9 Oct \\
Floyd & 1999 & 0900 UTC 17 Sep \\
Gustav & 2002 & 0000 UTC 12 Sep \\
Hanna & 2008 & 0900 UTC 7 Sep \\
\hline
\end{tabular}

present in these regions (with the low pressure system located to the south or west) and the ageostrophic frontogenesis acts as a mesoscale ascent-focusing mechanism in the SLRV (Roebber and Gyakum 2003; Razy et al. 2012).

The complete partitioning methodology and results are as follow.

- Group A (active cases, $n=19$ ) includes cases (Table 1 ) that meet the following five criteria:

- The ageostrophic frontogenesis at $t=0 \mathrm{~h}$ exceeds $150 \times 10^{-2} \mathrm{~K}(100 \mathrm{~km})^{-1}(3 \mathrm{~h})^{-1}$ and is oriented parallel to the long axis of the SLRV.

TABLE 3. Group C cases $(n=14)$; cases not selected for further analysis. Listed are $t=0 \mathrm{~h}$ and the reason each case did not meet the criteria for further study, as described in section $3 \mathrm{~b}$.

\begin{tabular}{|c|c|c|c|}
\hline Storm & Year & $t=0 \mathrm{~h}$ & $\begin{array}{l}\text { Reason dropped } \\
\text { from study }\end{array}$ \\
\hline Alberto & 1988 & 0000 UTC 8 Aug & $\begin{array}{l}\text { SLP center not } \\
\text { identifiable }\end{array}$ \\
\hline Hugo & 1989 & 0600 UTC 23 Sep & $\begin{array}{l}\text { Lack of northeasterly } \\
\text { surface winds }\end{array}$ \\
\hline Bertha & 1990 & 0900 UTC 2 Aug & $\begin{array}{l}\text { Lack of northeasterly } \\
\text { surface winds }\end{array}$ \\
\hline Not named & 1991 & 1200 UTC 2 Nov & $\begin{array}{l}\text { Influence of another } \\
\text { cyclone }\end{array}$ \\
\hline Beryl 1994 & 1994 & 0300 UTC 19 Aug & $\begin{array}{l}\text { Influence of another } \\
\text { cyclone }\end{array}$ \\
\hline Barry & 1995 & 0900 UTC 9 Jul & $\begin{array}{l}\text { Lack of northeasterly } \\
\text { surface winds }\end{array}$ \\
\hline Opal & 1995 & 1200 UTC 6 Oct & $\begin{array}{l}\text { Lack of northeasterly } \\
\text { surface winds }\end{array}$ \\
\hline Dennis 1999 & 1999 & 2100 UTC 7 Sep & $\begin{array}{l}\text { SLP center not } \\
\text { identifiable }\end{array}$ \\
\hline Gordon & 2000 & 1200 UTC 20 Sep & $\begin{array}{l}\text { Influence of another } \\
\text { cyclone }\end{array}$ \\
\hline Isabel & 2003 & 1800 UTC 19 Sep & $\begin{array}{l}\text { Lack of northeasterly } \\
\text { surface winds }\end{array}$ \\
\hline Hermine & 2004 & 1500 UTC 30 Aug & $\begin{array}{l}\text { SLP center not } \\
\text { identifiable }\end{array}$ \\
\hline Dennis 2005 & 2005 & 2100 UTC $17 \mathrm{Jul}$ & $\begin{array}{l}\text { SLP center not } \\
\text { identifiable }\end{array}$ \\
\hline Beryl 2006 & 2006 & 0600 UTC 21 Jul & $\begin{array}{l}\text { Influence of another } \\
\text { cyclone }\end{array}$ \\
\hline Noel & 2007 & 0900 UTC 4 Nov & $\begin{array}{l}\text { Lack of northeasterly } \\
\text { surface winds }\end{array}$ \\
\hline
\end{tabular}



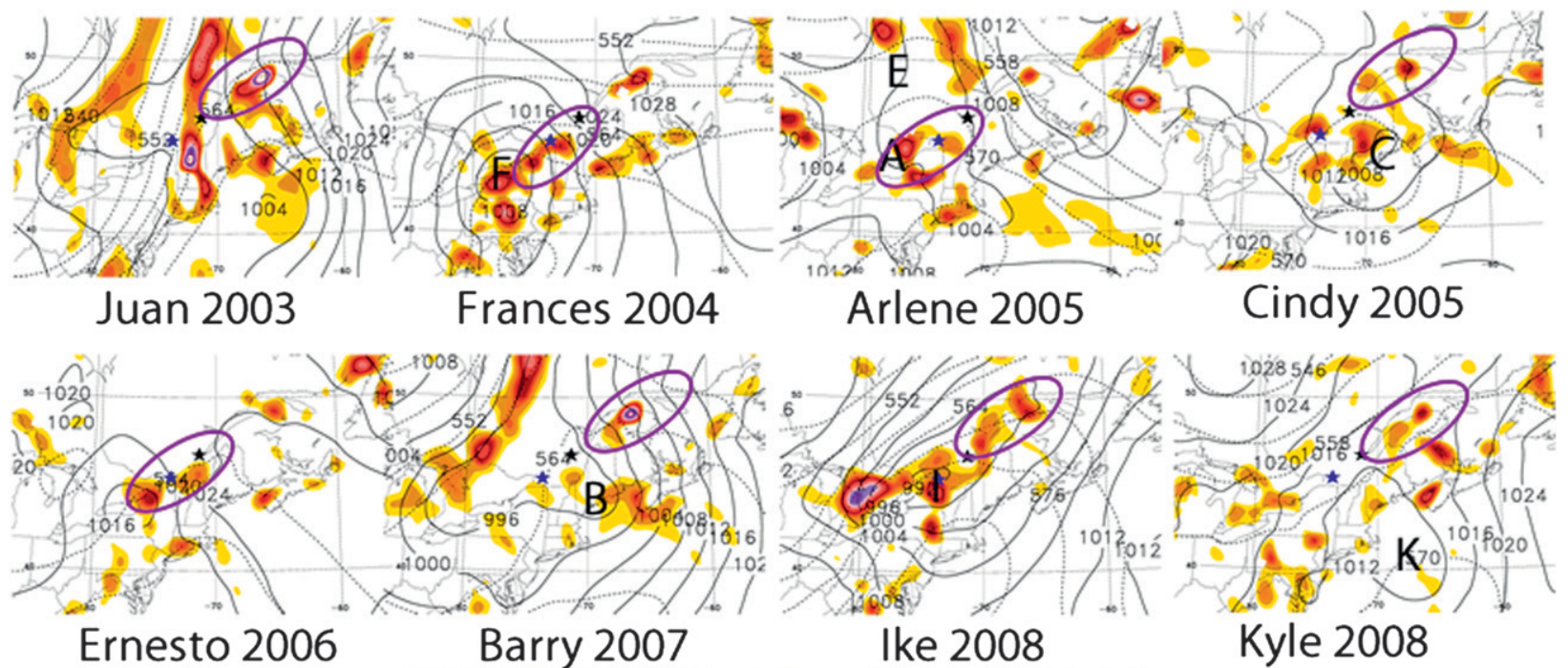

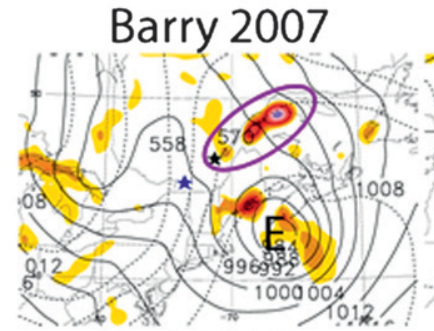

Earl 2010
Ike 2008

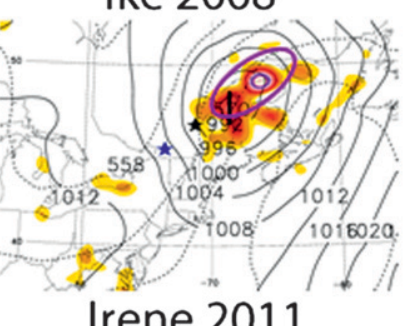

Kyle 2008

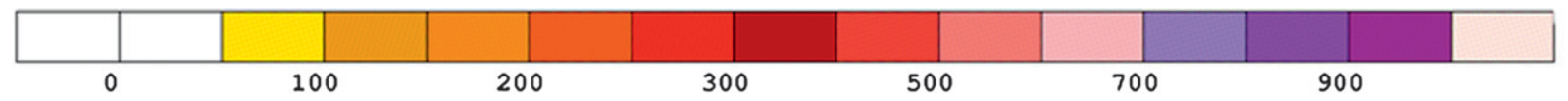

FIG. 4. NARR ageostrophic frontogenesis wherein the ageostrophic wind is the total wind at $30 \mathrm{~m}$ minus the geostrophic wind calculated from SLP [shaded, $\times 10^{-2} \mathrm{~K}(100 \mathrm{~km})^{-1}(3 \mathrm{~h})^{-1}$ ], SLP (hPa, solid black), and 1000-500-hPa thickness (dam, black dashed), for the 10 group A cases from 2003 to 2011, all at $t=0 \mathrm{~h}$. The center of each storm is marked by the first letter of the storm name. For reference, CYUL is marked with a blue star and CYQB is marked with a black star. The location of interest (ageostrophic frontogenesis) in the SLRV is marked with a purple oval. The remaining group A cases are available for viewing online (see Supplement 2).

- The center of the (former) tropical cyclone is discernible in the NARR SLP field.

- The 30-m NARR total wind is northeasterly (channeled down the valley) in the region of ageostrophic frontogenesis.

- At $t=0 \mathrm{~h}$, there must be an along-valley pressure gradient with lower pressure to the west.

- At $t=0 \mathrm{~h}$, the wind direction difference between the $30-\mathrm{m}$ wind and the geostrophic wind in the SLRV must be more than $20^{\circ}$.

- Group B (null cases, $n=5$ ) includes cases (Table 2) in which the ageostrophic frontogenesis threshold criterion $\left[>150 \times 10^{-2} \mathrm{~K}(100 \mathrm{~km})^{-1}(3 \mathrm{~h})^{-1}\right]$ was not met at $t=0 \mathrm{~h}$.

- Group C (cases not selected for further analysis, $n=$ 14) includes cases that were left out of group A for one of the following three reasons (Table 3):
- the center of circulation of the (former) tropical cyclone in the NARR was undetectable $(n=4)$; if the SLP field is unreliable, the ageostrophic wind calculations likely will be as well;

- northeasterly $30-\mathrm{m}$ winds were not found in the region of ageostrophic frontogenesis $(n=6)$; this suggests that the ageostrophic frontogenesis was due to processes unrelated to wind channeling and, thus, unrelated to the orography (Roebber and Gyakum 2003; Carrera et al. 2009; Razy et al. 2012); or

- the ageostrophic frontogenesis at $t=0 \mathrm{~h}$ was judged (albeit subjectively) to be due to synopticscale systems in northern Quebec, and was not attributed to the (former) tropical cyclone ( $n=$ 4). The goal of this study is to isolate the impacts of SLRV orography on precipitation associated with the transitioning tropical cyclone, not other synoptic-scale systems. 


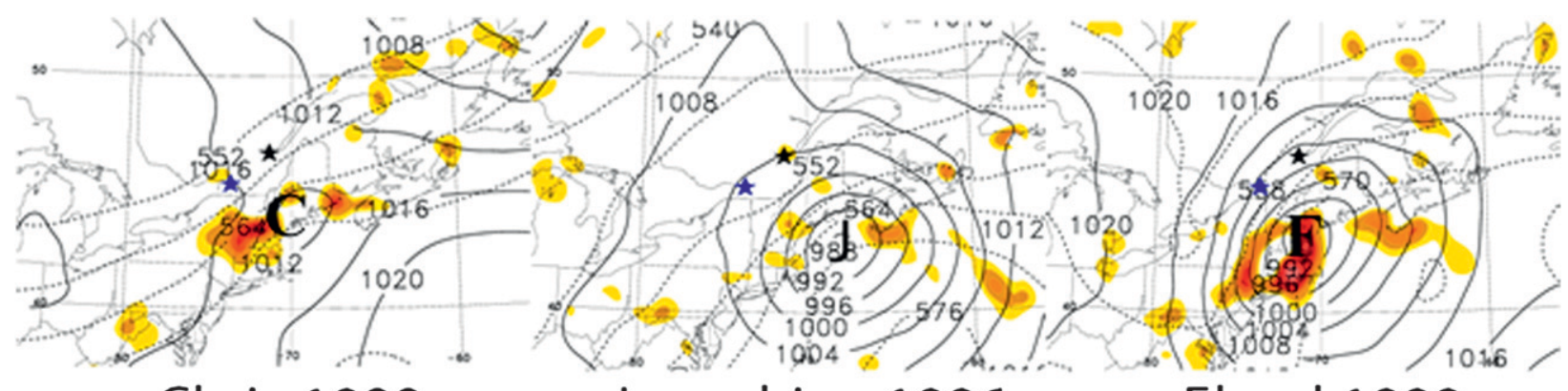

\section{Chris 1988}
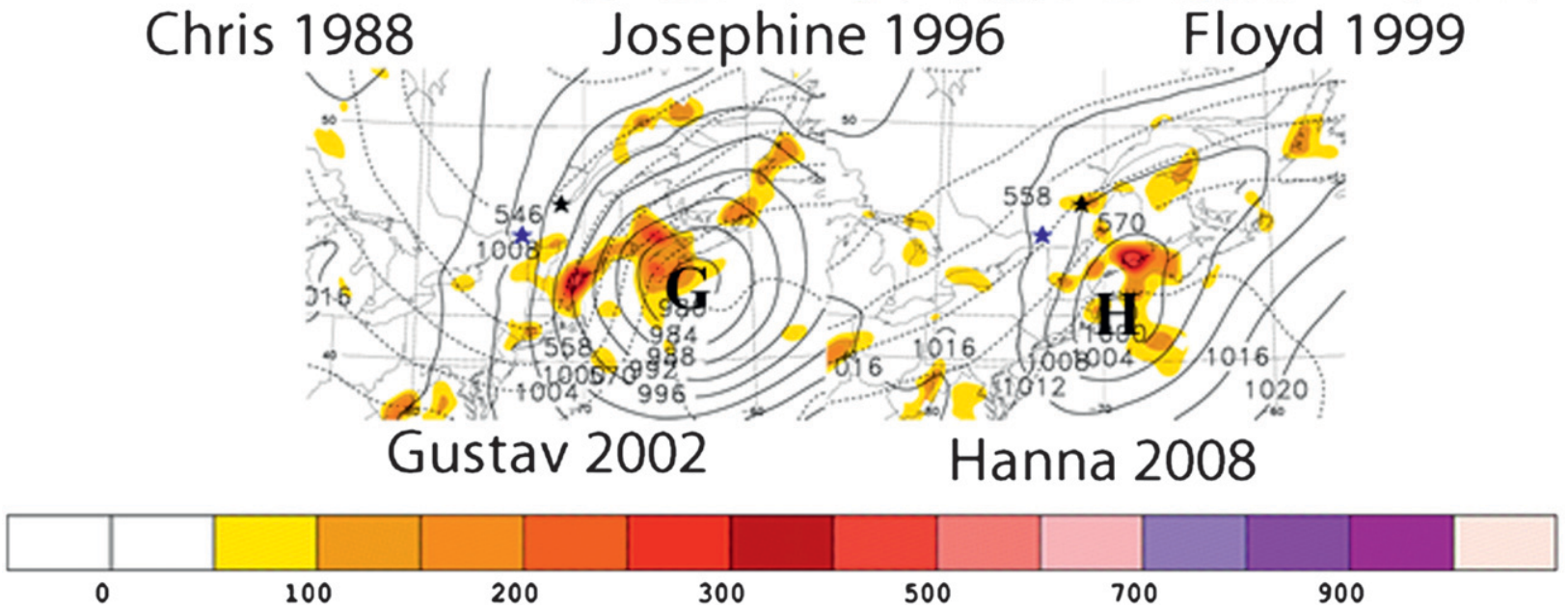

FIG. 5. As in Fig. 4, but for all group B cases $(n=5)$.

The last two criteria in group A are established to separate cases of pressure-driven channeling from forced channeling and downward momentum transport, in which the geostrophic wind direction and channeled wind direction are similar (Carrera et al. 2009; Razy et al. 2012). These processes will be discussed further in section $4 \mathrm{a}$.

The remainder of this paper will explore the contrast in dynamics between groups A and B, as well as focus on the impact of group A cases on precipitation in the SLRV. The dynamics of group $\mathrm{C}$ cases are available for viewing in the online supplement to this paper (Supplement 2).

\section{Synoptic-dynamic analysis}

\section{a. Frontogenesis}

Figure 4 shows a sample of the 19 group A cases. We chose the group A cases from 2003 to 2011, since that is the time period for which we have precipitation (CaPA) data. The group A cases not shown (1979-2002) can be viewed online (see Supplement 2). The location of ageostrophic frontogenesis for each group A case is marked in Table 1. The ageostrophic frontogenesis at $t=0 \mathrm{~h}$ occurs in two different areas of the SLRV. For example, in the case of Frances (2004), the ageostrophic frontogenesis is located in the southwestern SLRV, from CYUL southwestward toward Lake Ontario (Fig. 4). In contrast, during the approach of Barry (2007), the ageostrophic frontogenesis is located in the northeastern SLRV, northeast of Quebec City (CYQB) (Fig. 4). In cases where more than one area of ageostrophic frontogenesis is present, the area listed in Table 1 is that which is closest to the storm center. These areas were chosen because they were the most likely to be collocated with precipitation, given that enhanced precipitation is the focus of this study. Within group A $(n=19)$, there are 15 cases in which the ageostrophic frontogenesis is located in the northeastern SLRV, and 4 cases in the southwestern SLRV (Table 1).

Figure 5 shows the group B $(n=5)$ null cases. None of the group B cases track directly through the SLRV, in contrast to several group A cases (Figs. 4 and 5). Moreover, Fig. 5 shows that the pressure gradients within the SLRV are generally weak, with the isobars parallel to the long axis of the SLRV (e.g., Floyd 1999).

In Fig. 6, two cases from groups A and B are presented to examine the $30-\mathrm{m}$ wind and potential temperature fields used to calculate the ageostrophic frontogenesis, as the latter is a highly derived field. In the cases of Juan (2003) and Frances (2004) (Figs. 6a,b), northeasterly 30-m 

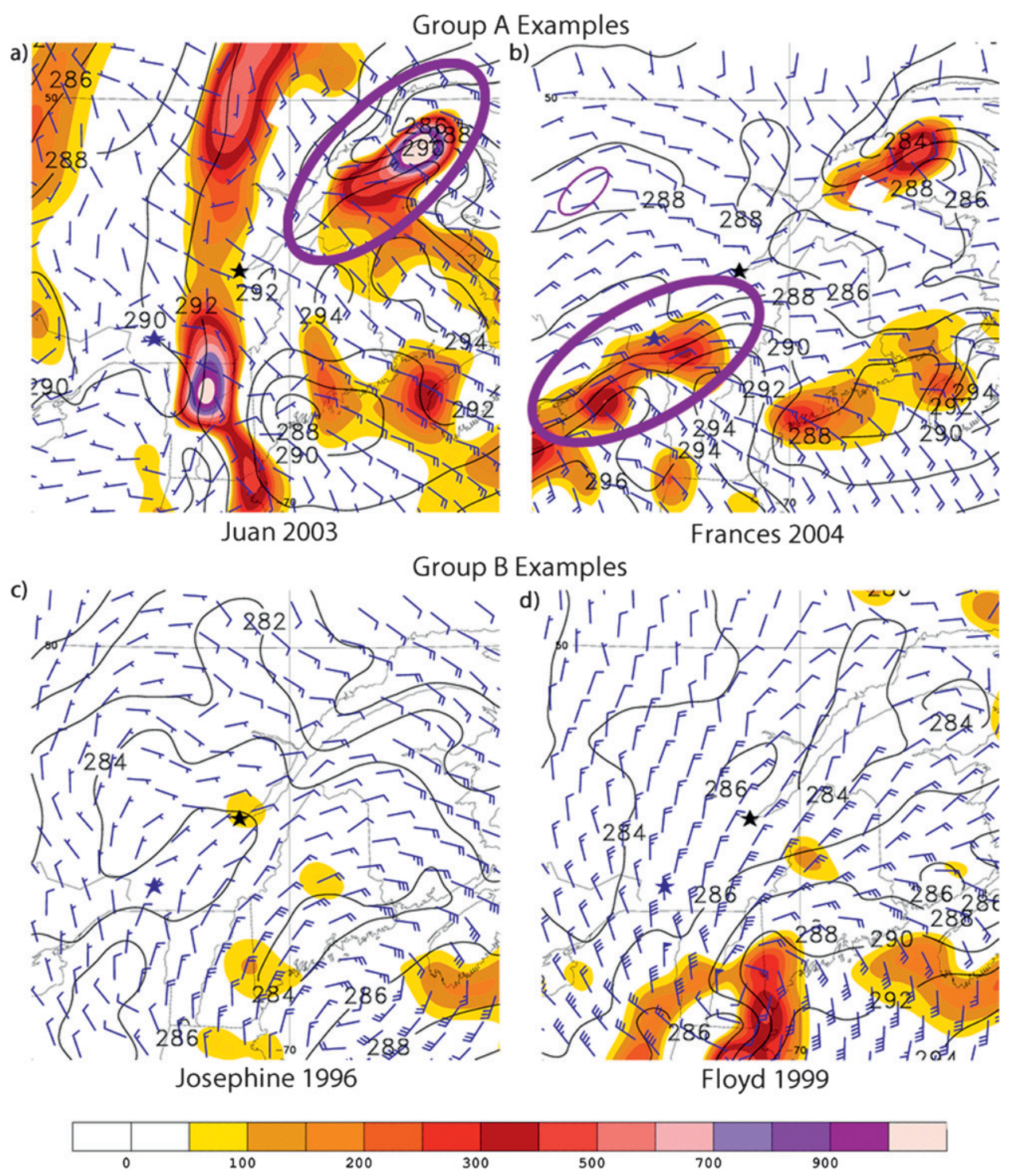

FIG. 6. NARR ageostrophic frontogenesis at $t=0 \mathrm{~h}$, as in Fig. 4 (shaded), 30-m total wind (kt, barbs), and 30-m potential temperature ( $\mathrm{K}$, black contours) for two group A cases: (a) Juan (2003) and (b) Frances (2004), and two group B cases: (c) Josephine (1996) and (d) Floyd (1999). In (a) and (b), the purple oval highlights the zoomed-in region of interest as in Fig. 4. The remaining cases from all groups are available for viewing online (see Supplement 3).

winds within the SLRV are collocated with areas of ageostrophic frontogenesis (regions marked by purple ovals). Furthermore, the $30-\mathrm{m}$ wind directions outside the SLRV are quite different than the northeasterlies within the SLRV. For Juan (2003), Fig. 6a shows that the 30-m winds are almost entirely southeasterly outside of the SLRV. For Frances (2004), Fig. 6b shows that the 30-m winds south of the SLRV are southeasterly, while winds to the north of the Ottawa River valley and SLRV are easterly or east-northeasterly. The spatial change in wind direction sets the stage for the ageostrophic frontogenesis located within the SLRV.
In contrast, Figs. $6 \mathrm{c}$, d show the $30-\mathrm{m}$ wind and potential temperature for two group B cases. During both Josephine (1996) and Floyd (1999) (Figs. 6c,d), the $30-\mathrm{m}$ winds within the SLRV are almost entirely northeasterly. In addition, the wind directions in the adjacent regions outside the valley are also northeasterly (Figs. 6c,d). These wind directions correspond to the geostrophic wind directions in these cases (Fig. 5). Thus, it is likely that downward momentum transport or forced channeling (Razy et al. 2012) is occurring in the SLRV in group B cases. However, the definitions of forced channeling and downward 


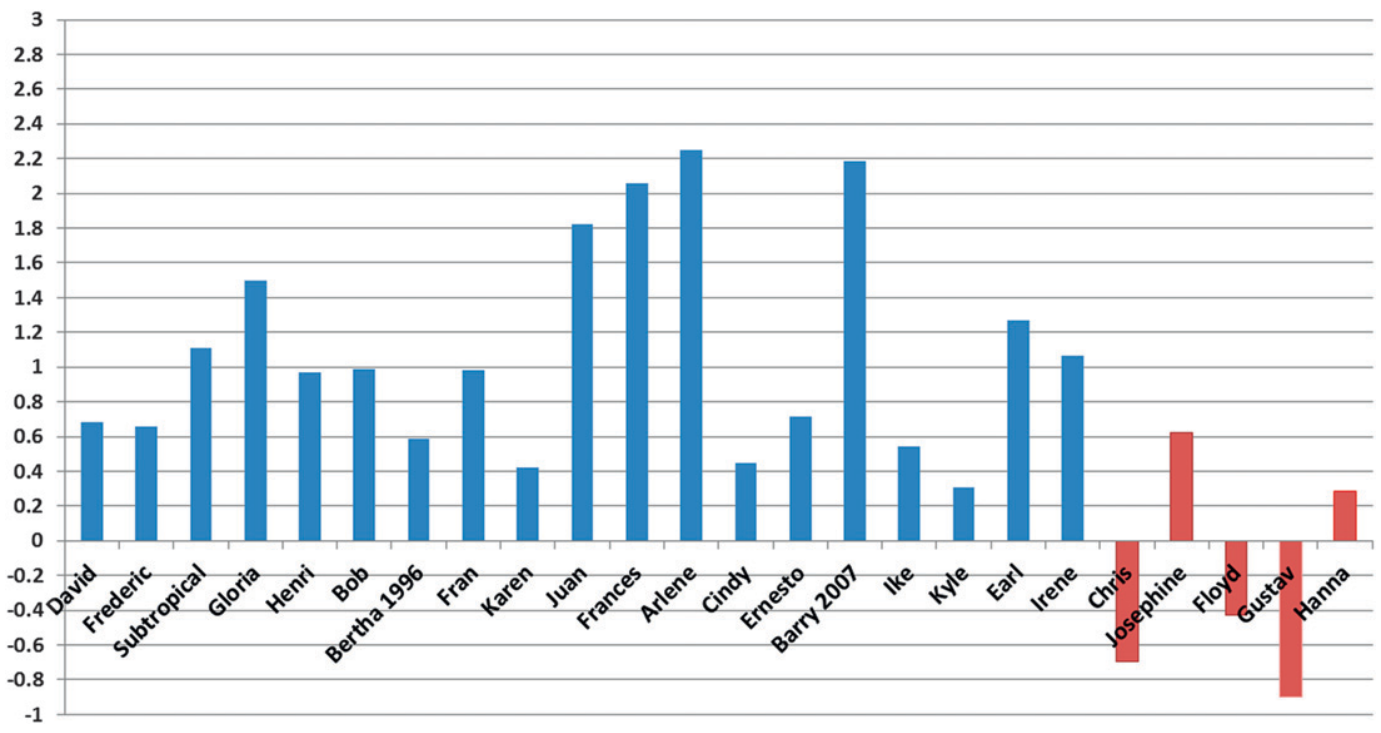

FIG. 7. NARR SLP gradients $\left[\mathrm{hPa}(100 \mathrm{~km})^{-1}\right]$ at $t=0 \mathrm{~h}$ along the SLRV for groups A (blue, $\left.n=19\right)$ and B (red, $n=5$ ). Pressure differences were calculated by subtracting the SLP at the closest point in the SLRV to the cyclone center from the SLP at the end of the SLRV $\left(49.75^{\circ} \mathrm{N}, 64.5^{\circ} \mathrm{W}\right)$, i.e., northeast minus southwest.

momentum transport require that the channeled wind direction be similar to the geostrophic wind direction, meaning that the surface wind directions in and outside of the SLRV will be very similar. This setup is not favorable to ageostrophic frontogenesis (Figs. 6c,d). Similar structures are evident in the remainder of the group A and B cases (see Supplement 3). As such, we consider group A cases to be primarily associated with pressure-driven channeling (Carrera et al. 2009; Razy et al. 2012).

In group A cases, there is implied strong cold potential temperature advection in the region of northeasterly 30-m winds and ageostrophic frontogenesis (Figs. 6a,b), as evidenced by the strong buckling (analogous to, e.g., a thickness trough) of potential temperature contours in the SLRV. Meanwhile, much weaker or no cold advection is implied in group B cases (Figs. 6c,d, respectively). Similar results are seen in other group A and B cases, respectively (see Supplement 3 ). The stronger buckling of the potential temperature contours in the region of northeasterly winds (Figs. 6a,b) in group A cases further supports our assertion of pressure-driven wind channeling, as colder surface air from northeastern Quebec is advected toward the southwest along the axis of the SLRV. This finding has implications for static stability, which is discussed in section $4 \mathrm{c}$.

Carrera et al. (2009) and Razy et al. (2012) found that pressure-driven channeling dominates in the SLRV when there is an established pressure gradient from one end of the SLRV to the other. Thus, we calculated the pressure gradient in the SLRV for all group A and B events at $t=0 \mathrm{~h}$ using

$$
\left(\frac{\Delta p}{\Delta n}\right)(100 \mathrm{~km})
$$

where $\Delta p$ is the magnitude of the sea level pressure (SLP) difference in the SLRV. The pressure differences were calculated by subtracting the SLP at the point in the SLRV closest to the center of the transitioning tropical cyclone from the SLP at the northeastern end of the SLRV [Eq. (2)], located at the mouth of the Gulf of St. Lawrence $\left(49.75^{\circ} \mathrm{N}, 64.5^{\circ} \mathrm{W}\right)$. We calculated the pressure gradient by dividing it by the distance $(\Delta n)$ over which $\Delta p$ was calculated. The results are listed in units of $\mathrm{hPa}(100 \mathrm{~km})^{-1}$ so that the values may be more intuitive to operational forecasters.

Figure 7 shows that 18 of 19 group A cases have pressure gradients larger than $0.4 \mathrm{hPa}(100 \mathrm{~km})^{-1}$, while the same can be said for only 1 of 5 cases in group B. Moreover, eight cases in group A (e.g., Frances in 2004) are associated with pressure gradients exceeding $1 \mathrm{hPa}$ $(100 \mathrm{~km})^{-1}$ (Fig. 7). These findings are highly suggestive of pressure-driven channeling.

Figures $8 \mathrm{a}$ and $8 \mathrm{~b}$ present composite analyses for groups A and B, respectively. Since 4 of 19 group A cases had ageostrophic frontogenesis located in the southwestern SLRV (Table 1), we aim to limit composite smearing by only compositing the 15 group A cases with ageostrophic frontogenesis in the northeastern SLRV (Table 1). Figure 8a shows that the only northeasterly 


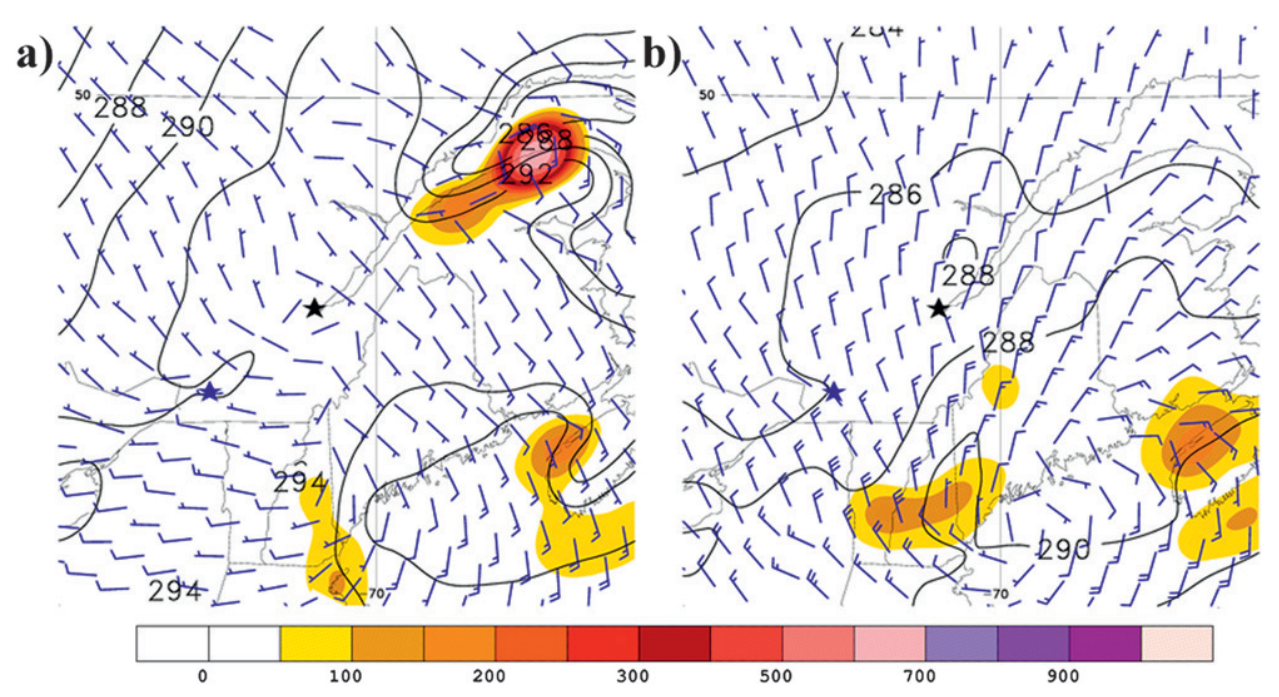

FIG. 8. As in Fig. 6, but for NARR composites of (a) group A cases with ageostrophic frontogenesis located in the northeastern SLRV $(n=15)$ and (b) group B cases $(n=5)$.

30-m NARR winds found in Fig. 8a are within the SLRV and are collocated with the ageostrophic frontogenesis. The 30-m winds to the north and south of the SLRV are primarily from the southeast. Moreover, the surface cold-air advection signature observed in individual cases (Figs. 6a,b) is also present in the composite (Fig. $8 a)$. This finding has important ramifications for the lowlevel static stability in developing a near-surface temperature inversion, discussed further in section $4 \mathrm{c}$.

Figure $8 \mathrm{~b}$ shows that in the group B (null case) composite, $30-\mathrm{m}$ winds are generally in the same direction (northeasterly) both within and outside of the SLRV, suggesting forced channeling or downward momentum transport. This setup is not conducive to ageostrophic frontogenesis, since the winds are largely from the same direction (nearly geostrophic) both within and outside of the SLRV. In addition, the northeasterly winds located in the northeastern SLRV (Fig. 8b) are weaker than those in the group A composite (Fig. 8a), perhaps explaining the relative lack of surface cold-air advection in group B cases.

Finally, structures in the northeastern SLRV (Figs. 6a and $8 \mathrm{a}, \mathrm{b})$ are also consistent with coastal frontogenesis (Bosart et al. 1972; Bosart 1975). The climatological SSTs in the northeastern SLRV during the Atlantic tropical season range from 284 to $289 \mathrm{~K}$ (available online at the St. Lawrence Global Observatory; http://www. slgo.ca). Figure 8a shows that the composite 30-m potential temperatures correspond to these values. Since we assume the land surface temperatures to the south to be warmer, it is logical to think that the land-SST difference is a contributor to the magnitude of the temperature gradient and, thus, the ageostrophic frontogenesis
(Fig. 8a). In group B cases (Figs. 6c,d and 8), the composite $30-\mathrm{m}$ potential temperatures in the northeastern SLRV also agree with the climatological SSTs, but the potential temperatures over land are lower than in group A (Figs. 6a and 8a), reducing the land-sea temperature contrast and thus the coastal frontogenesis contribution.

\section{b. Precipitation}

To analyze the precipitation distributions in the SLRV, we focus on 10 group A cases from 2003 to 2011, in accordance with the availability of the CaPA (Mahfouf et al. 2007). Figure 9 displays two-panel figures of all 10 cases, in order to compare the orientation of the precipitation to that of the valley-induced ageostrophic frontogenesis. In Fig. 9, the left-hand panels show the total ageostrophic frontogenesis for the 6-h period surrounding $t=0 \mathrm{~h}$ (i.e., from $t=-3 \mathrm{~h}$ to $t=+3 \mathrm{~h}$ ). The right-hand panels in Fig. 9 show the CaPA precipitation totals for the 12-h period surrounding $t=0 \mathrm{~h}$ (Table 4). Using values summed over several time periods avoids problems caused by trying to compare instantaneous values of ageostrophic frontogenesis at $t=0 \mathrm{~h}$ with 6-h precipitation totals. Although the greatest ageostrophic frontogenesis in a particular case occurs at $t=0 \mathrm{~h}$, ageostrophic frontogenesis is still present at neighboring times. Since precipitation accumulation is not an instantaneous field, the ageostrophic frontogenesis at neighboring times can still have an impact on precipitation amounts. As an example, during the passage of Ike (2008), $t=0 \mathrm{~h}$ is 0600 UTC 15 September, so the CaPA-accumulated precipitation shown in Fig. 9 is from 0000 to 1200 UTC 15 September (Table 4). 

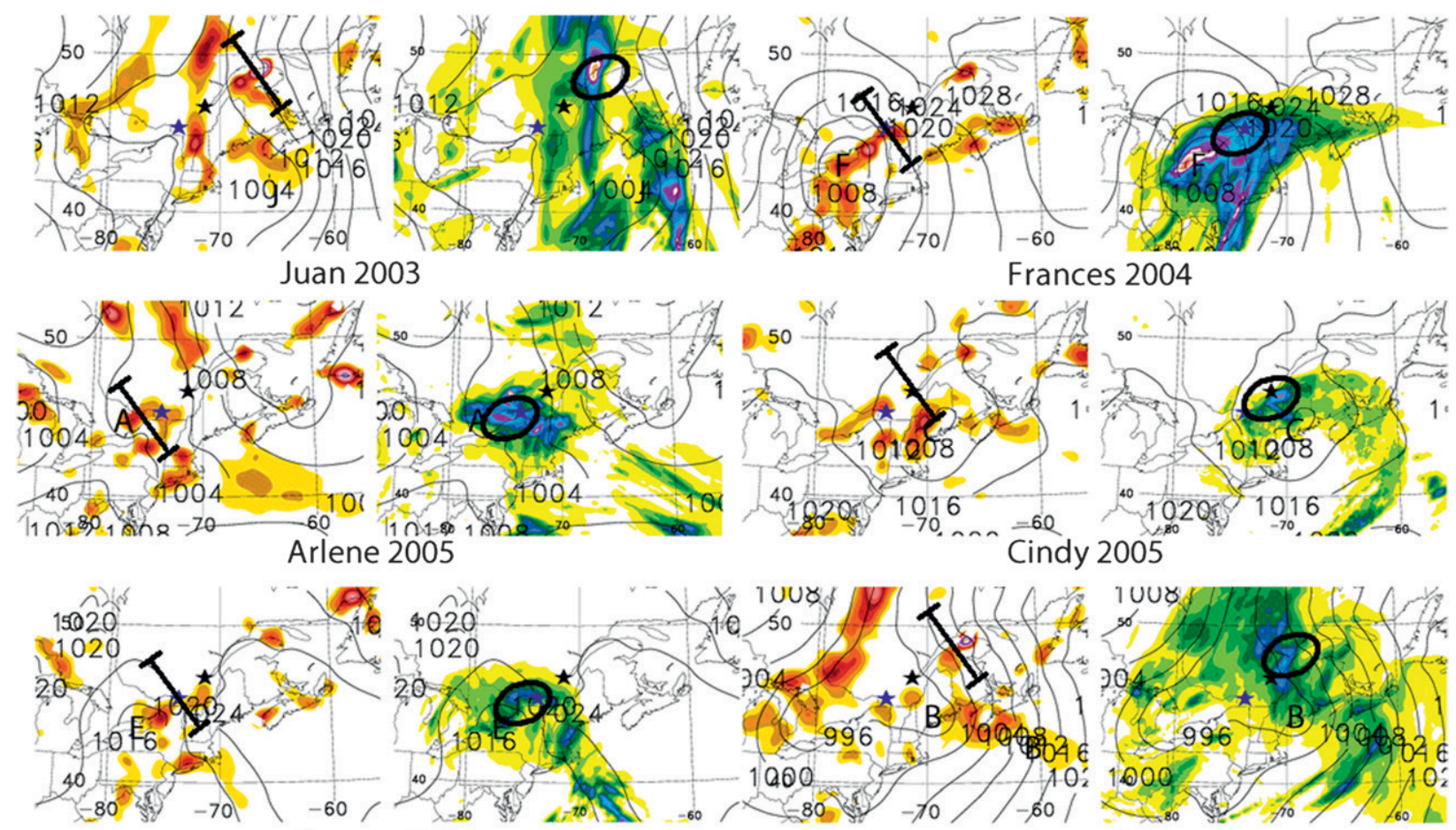

Ernesto 2006
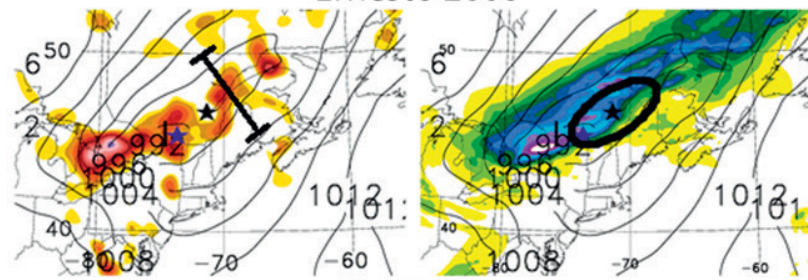

Barry 2007

Ike 2008

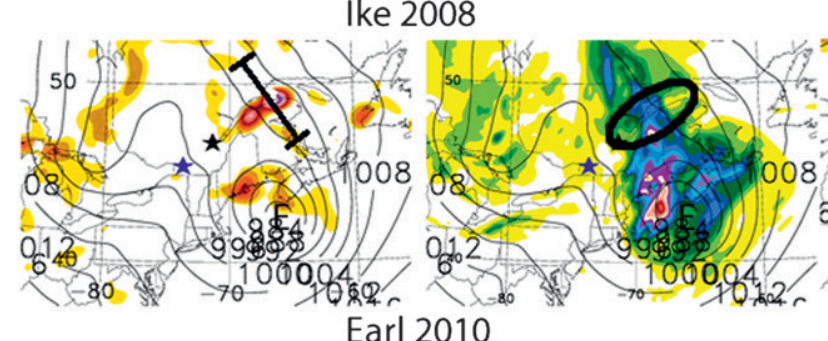

Earl 2010

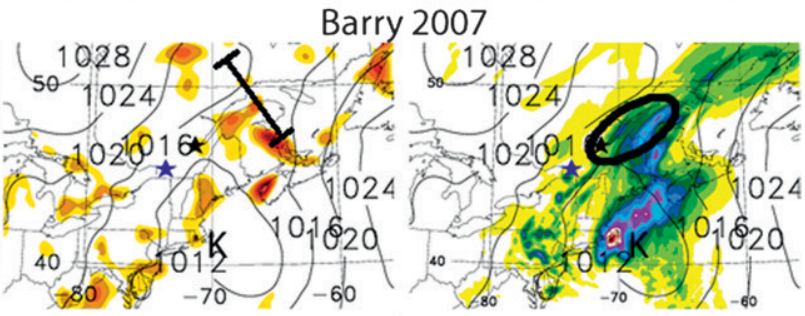

Kyle 2008

Frontogenesis $(\mathrm{K} / 100 \mathrm{~km} / 3 \mathrm{hr})$
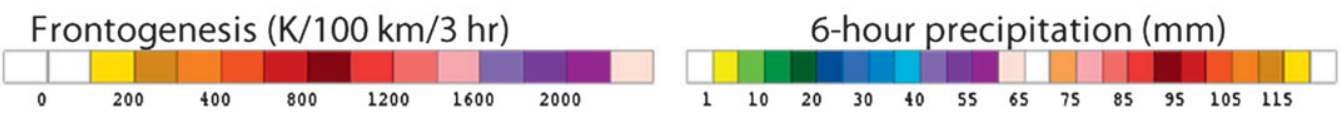

FIG. 9. For the 10 group A cases from 2003 to 2011, (left for each storm) as in Fig. 4, but here the ageostrophic frontogenesis is the total from $t=-3 \mathrm{~h}$ to $+3 \mathrm{~h}$. The center of each storm is marked with the first letter of the storm name and the lines denote the cross sections taken in Fig. 11. (right for each storm) CaPA total precipitation ( $\mathrm{mm}$, shaded) for the 12-h period listed in Table 4 and NARR SLP (hPa, solid black contours) at $t=0 \mathrm{~h}$. The black ovals denote the area of enhanced precipitation in the SLRV. In all panels, CYUL is marked with a blue star CYQB is marked with a black star, for reference.

Figure 9 shows qualitative evidence that in group A cases from 2003 to 2011, areas of enhanced precipitation are collocated with areas of ageostrophic frontogenesis, and both are oriented parallel to either the SLRV or the Ottawa River valley (a westward extension of the
SLRV; Fig. 1b). For example, during the approaches of Frances (2004) and Ike (2008), an axis of heavy precipitation is oriented parallel to the SLRV from the eastern end of Lake Ontario to CYUL (Fig. 9). The axis of heaviest precipitation is collocated with the ageostrophic 
TABLE 4. The 10 group A cases from 2003 to 2011, $t=0$, and the 12-h precipitation periods used for the right-hand panels in Fig. 9.

\begin{tabular}{|c|c|c|c|}
\hline Storm & Year & $t=0 \mathrm{~h}$ & $\begin{array}{l}\text { CaPA } 12 \text {-h precipitation } \\
\text { period in Fig. } 9\end{array}$ \\
\hline Juan & 2003 & 0000 UTC 29 Sep & $\begin{array}{l}1800 \text { UTC } 28 \text { Sep-0600 UTC } \\
29 \text { Sep }\end{array}$ \\
\hline Frances & 2004 & 1500 UTC 9 Sep & 0600-1800 UTC 9 Sep \\
\hline Arlene & 2005 & 1500 UTC 14 Jun & 0600-1800 UTC 14 Jun \\
\hline Cindy & 2005 & 0300 UTC $10 \mathrm{Jul}$ & $\begin{array}{l}1800 \text { UTC } 9 \text { Jul-0600 UTC } \\
10 \mathrm{Jul}\end{array}$ \\
\hline Ernesto & 2006 & 1500 UTC 3 Sep & 0600-1800 UTC 3 Sep \\
\hline Barry & 2007 & 0600 UTC 5 Jun & 0000-1200 UTC 5 Jun \\
\hline Ike & 2008 & 0600 UTC 15 Sep & 0000-1200 UTC 15 Sep \\
\hline Kyle & 2008 & 1800 UTC 28 Sep & $\begin{array}{l}1200 \text { UTC } 28 \text { Sep-0000 UTC } \\
29 \text { Sep }\end{array}$ \\
\hline Earl & 2010 & 1200 UTC 4 Sep & 0600-1800 UTC 4 Sep \\
\hline Irene & 2011 & 0900 UTC 29 Aug & 0000-1200 UTC 29 Aug \\
\hline
\end{tabular}

frontogenesis, and both are oriented parallel to the long axis of the SLRV (Fig. 9). For Arlene (2005), both the ageostrophic frontogenesis and the axis of heaviest precipitation are located in the Ottawa River valley west of CYUL (Fig. 9), a region that is also prone to pressuredriven wind channeling (Carrera et al. 2009; Razy et al. 2012).

For the sake of comparison, the online supplement to this paper (see Supplement 5) shows plots as in Fig. 9 for one group B (Hanna 2008) and one group C (Hermine 2004) case for which CaPA data were available. Unlike in group A cases (Fig. 9), there is no enhancement of precipitation in the SLRV evident in Hanna (2008) or Hermine (2004). This is supportive of the observed collocation of ageostrophic frontogenesis and enhanced precipitation. The association between ageostrophic frontogenesis and enhanced precipitation is analyzed physically and discussed further in section $4 \mathrm{c}$.

Figure 10 shows a composite of $\mathrm{CaPA}$ precipitation for the 10 cases in Fig. 9, along with the location of the center of each transitioning cyclone in the composite. At $t=-12 \mathrm{~h}$ (Fig. 10a), most of the composite precipitation is located in New York and New England, and is not yet in the SLRV. By $t=-6 \mathrm{~h}$ (Fig. 10b), two areas of enhanced precipitation are evident in the SLRV: 1) the region between Lake Ontario and CYUL and 2) the region northeast of CYQB. This observation corresponds to the fact that 3 of the 10 cases in the composite have ageostrophic frontogenesis in the southwestern SLRV, while the remaining 7 cases have ageostrophic frontogenesis in the northeastern SLRV. This bifurcation is also evident at $t=0 \mathrm{~h}$ (Fig. 10c), where precipitation in the SLRV is enhanced compared to regions north and south of the valley. By $t=+6 \mathrm{~h}$ (Fig. 10d), the axis of heaviest precipitation is located in the northeastern SLRV.
The precipitation composites from $t=-6 \mathrm{~h}$ to $+6 \mathrm{~h}$ (Figs. 10b,d) show enhanced precipitation in the SLRV despite the fact that many of the cyclone centers are located outside of the SLRV. Along with the temperature and wind structures observed in Figs. 6 and 8, and the pressure gradient calculations shown in Fig. 7, this suggests that an approaching cyclone need only help to establish a synoptic-scale pressure gradient in the SLRV to have an impact on the precipitation distribution. The cyclone itself does not actually have to be located within the SLRV, although in some cases it is (Figs. 10b,d).

\section{c. Dynamic mechanisms for ascent and static stability}

Because the SLRV is a broad and shallow valley (Carrera et al. 2009; Razy et al. 2012), the valley-induced ageostrophic frontogenesis observed in group A cases (Figs. 4 and 6) is likely a relatively shallow phenomenon. The goal of this section is to suggest a physical pathway between shallow ageostrophic frontogenesis and ascent and precipitation.

Using Eq. (1), the geostrophic frontogenesis can be written as Eq. (3), from Bluestein (1993, p. 307), where the wind field is geostrophic and natural coordinates are assumed such that $\partial \theta / \partial x=0$. The geostrophic frontogenesis is related to QG forcing for ascent via Eqs. (4) and (5), where Eq. (4) is from Bluestein (1993, p. 307) and Eq. (5) is from Bluestein (1992, p. 353):

$$
\begin{aligned}
\mathbf{F}_{p} & =-\left(\begin{array}{c}
\frac{\partial v_{g}}{\partial x} \frac{\partial \theta}{\partial y} \\
\frac{\partial v_{g}}{\partial y} \frac{\partial \theta}{\partial y}
\end{array}\right), \\
\mathbf{Q} & =\frac{R}{\sigma p}\left(\frac{p}{p_{0}}\right)^{\kappa} \mathbf{F}_{p}, \quad \text { and } \\
\left(\nabla_{p}^{2}+\frac{f_{0}^{2}}{\sigma} \frac{\partial^{2}}{\partial p^{2}}\right) \omega & =-2 \nabla p \cdot \mathbf{Q} .
\end{aligned}
$$

Equation (4) relates the geostrophic frontogenesis to Q vectors, where $\mathbf{Q}$ is the $\mathbf{Q}$ vector, $\sigma$ is the static stability parameter, $p$ is the pressure, $p_{0}$ is some reference pressure, $\mathbf{F}_{p}$ is the vector frontogenesis function for the geostrophic wind, and $\kappa$ is $R$, the gas constant for dry air divided by $c_{p}$, the specific heat at constant pressure. Equation (5) is the Q-vector form of the inviscid adiabatic quasigeostrophic (QG) omega equation in which the direction of vertical motion is related to the divergence of the Q vector. Hoskins et al. (1978) further describes Eq. (5), stating that "in quasi-geostrophic theory ... vertical velocity is forced solely by the divergence of $\mathbf{Q}$." 


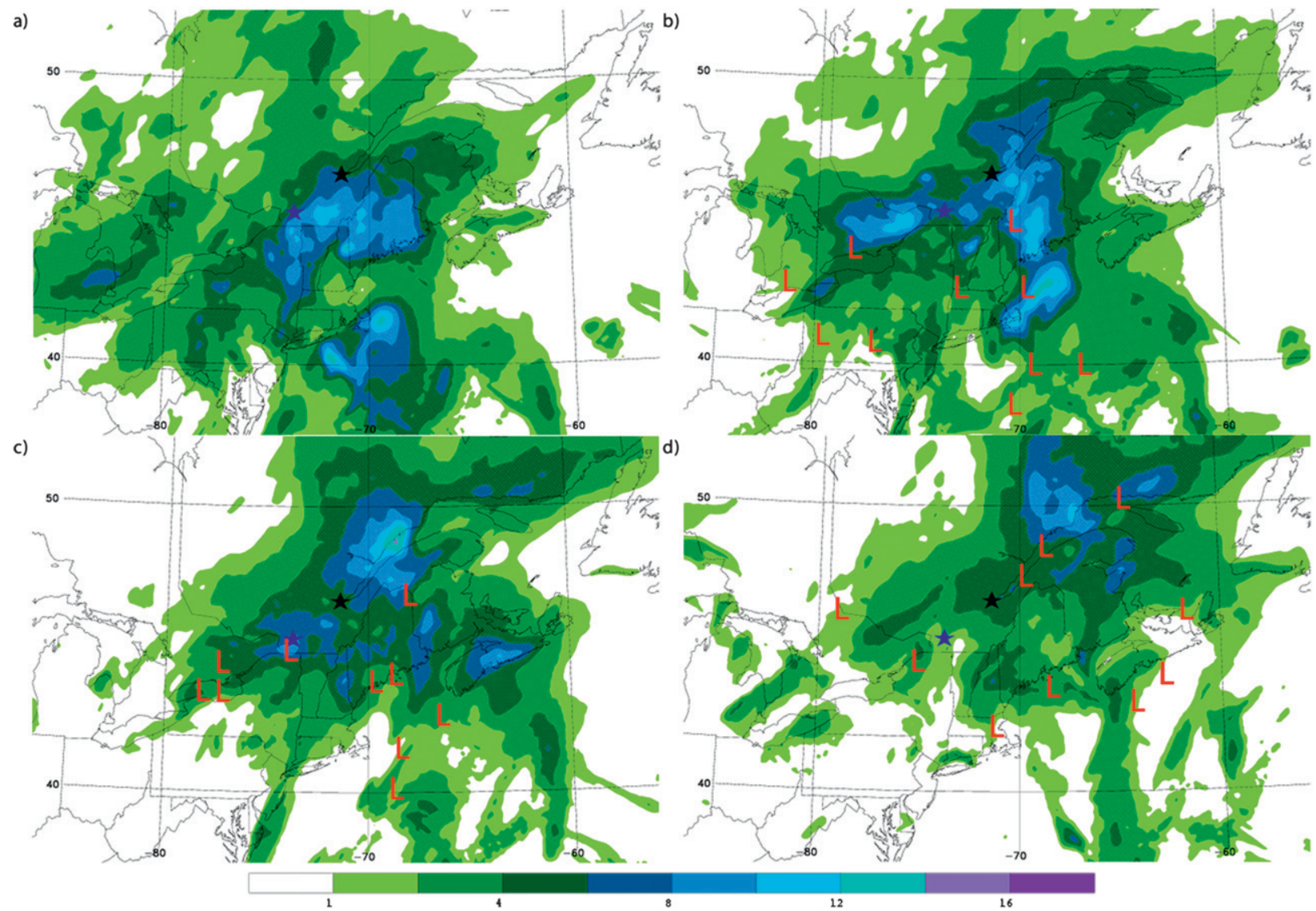

FIG. 10. For the 10 group A cases from 2003 to 2011, CaPA composite 6-hourly accumulated precipitation (mm, shaded) at $t=(\mathrm{a})-12$, (b) -6 , (c) 0 , and (d) +6 h. For each time, the accumulated precipitation is for the 6-h time period ending at that time. For (b)-(d), the location of the center of each cyclone in the composite, as identified from NARR SLP, is included (red L symbols). For reference, CYUL is marked with a blue star and CYQB is marked with a black star.

For each group A case from 2003 to 2011, Fig. 11 shows $1000-500-\mathrm{hPa}$ layer-averaged Q-vector divergence, sea level pressure, and 1000-500-hPa thickness at $t=0$ h. Utilizing Eqs. (4) and (5), we can conclude that areas of geostrophic frontogenesis and Q-vector convergence are associated with areas of synoptic-scale ascent and possible precipitation. We note that the Q-vector divergence field in Fig. 11 was not smoothed any more than the ageostrophic frontogenesis field was in Figs. 4 and 6, retaining the relatively high resolution of the NARR. Figure 11 shows that in several cases (e.g., Barry 2007), Q-vector divergence (associated with descent) is observed near the area of precipitation and ageostrophic frontogenesis (Fig. 9) in the SLRV. In other cases such as Ike (2008) and Frances (2004), Q-vector convergence is present, but is relatively equal in magnitude on either side of the SLRV, suggesting no preferential alignment of the large-scale ascent with the axis of SLRV. We can therefore infer that the enhanced precipitation along the SLRV (Figs. 9 and 10) is focused by lower-tropospheric mesoscale forcing for ascent, not synoptic-scale forcing or 1000-500-hPa geostrophic frontogenesis.

To assess static stability during our group A events, we use a combination of NARR cross-section (Fig. 12) and sounding (Fig. 13) analyses. For the cross sections, the criterion for convective (potential) instability (Bluestein 1992, p.222) is

$$
\frac{d \theta_{e}}{d z}<0,
$$

where $\theta_{e}$ is the equivalent potential temperature and $z$ is height.

In the left-hand panels in Fig. 9, the black vertical lines indicate areas chosen for cross-section analyses in Fig. 12. The cross sections are oriented from southeast to northwest through the areas of maximum ageostrophic frontogenesis, and perpendicular to the long axis of the SLRV, provided the ageostrophic frontogenesis is collocated 


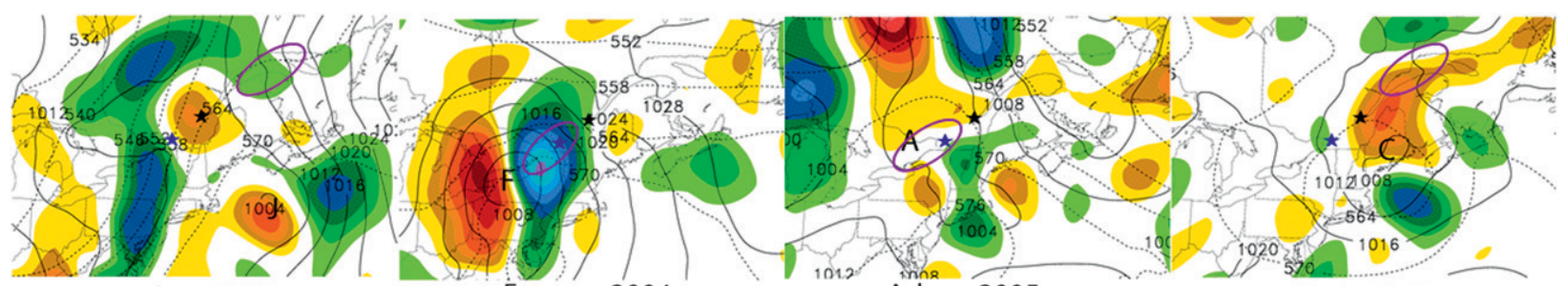

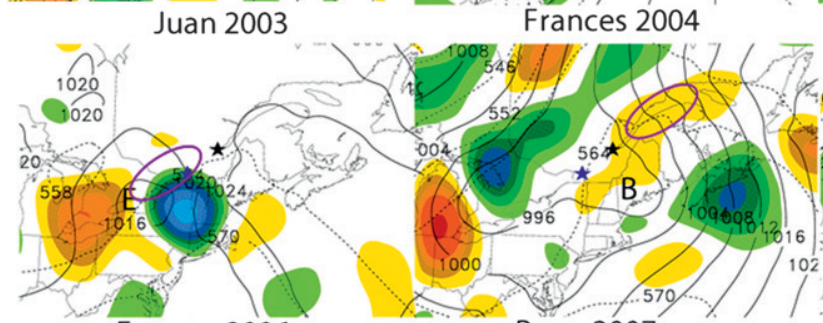

Ernesto 2006

Barry 2007

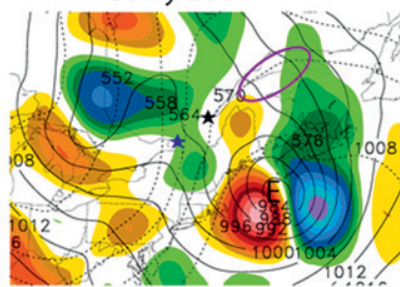

Earl 2010

1000-500 hPa Q-vector divergence

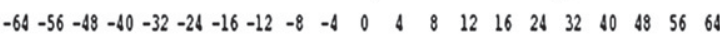

FIG. 11. For the 10 group A cases from 2003 to 2011, NARR $1000-500-\mathrm{hPa}$ layer-averaged Q-vector divergence $\left(\times 10^{-16} \mathrm{~K} \mathrm{~m}^{-2} \mathrm{~s}^{-1}\right.$; shaded cool colors for convergence, warm colors for divergence), SLP (hPa, solid black), and 1000-500-hPa thickness (dam, black dashed). The center of each storm is marked by the first letter of the storm name. The times shown are $t=0 \mathrm{~h}$ for each case, as listed in Table 1 . The location of interest (ageostrophic frontogenesis) in the SLRV is marked with a purple oval, as in Fig. 4. For reference, CYUL is marked with a blue star and CYQB is marked with a black star. The remaining group A cases are available for viewing online (see Supplement 4).

with regions of precipitation where precipitation data were available (Fig. 9). The center point of each cross section represents the region of ageostrophic frontogenesis in the SLRV, and is the location of each sounding in Fig. 13.

Figure 12 shows that for all 10 group A cases from 2003 to 2011 there is substantial low-level ageostrophic frontogenesis centered in the SLRV at $t=0 \mathrm{~h}$. The remaining group A cases show similar results (see Supplement 4). In most group A cases (e.g., Ernesto in 2006), low-level ageostrophic frontogenesis is not observed to the north or south of the SLRV, and is relatively shallow, roughly encompassing only the lowest $75-100 \mathrm{hPa}$ of the troposphere. In cases such as Irene (2011) where there is also ageostrophic frontogenesis outside the SLRV (Fig. 12), it is likely that not all of the ageostrophic frontogenesis can be attributed to the channeling within the SLRV (e.g., Rotunno et al. 1994). However, we suggest that channeling plays some role in the ageostrophic frontogenesis in all group A cases. To that end, the depth of the ageostrophic frontogenesis roughly corresponds to the terrain height of the SLRV (Fig. 1). In a couple of cases in Fig. 12 (e.g., Frances in 2004), a region of ageostrophic frontogenesis is present in the midtroposphere, but remains distinct from the low-level ageostrophic frontogenesis. The latter is likely due to pressure-driven wind channeling and the orography of the valley, and the former is not.

The equivalent potential temperature contours plotted in each panel in Fig. 12 are used to evaluate potential instability. There are two cases (Arlene in 2005, Cindy in 2005) that exhibit upright equivalent potential temperature contours and thus low potential stability. However, most cases (e.g., Juan in 2003) are associated with a potentially stable lower troposphere. The group A cases in Fig. 12 were also examined for regions of conditional symmetric (slantwise) instability (CSI, not shown), but all cases were found to be lacking CSI. Thus, we turn our focus to an examination of conditional instability, using the soundings in Fig. 13. 

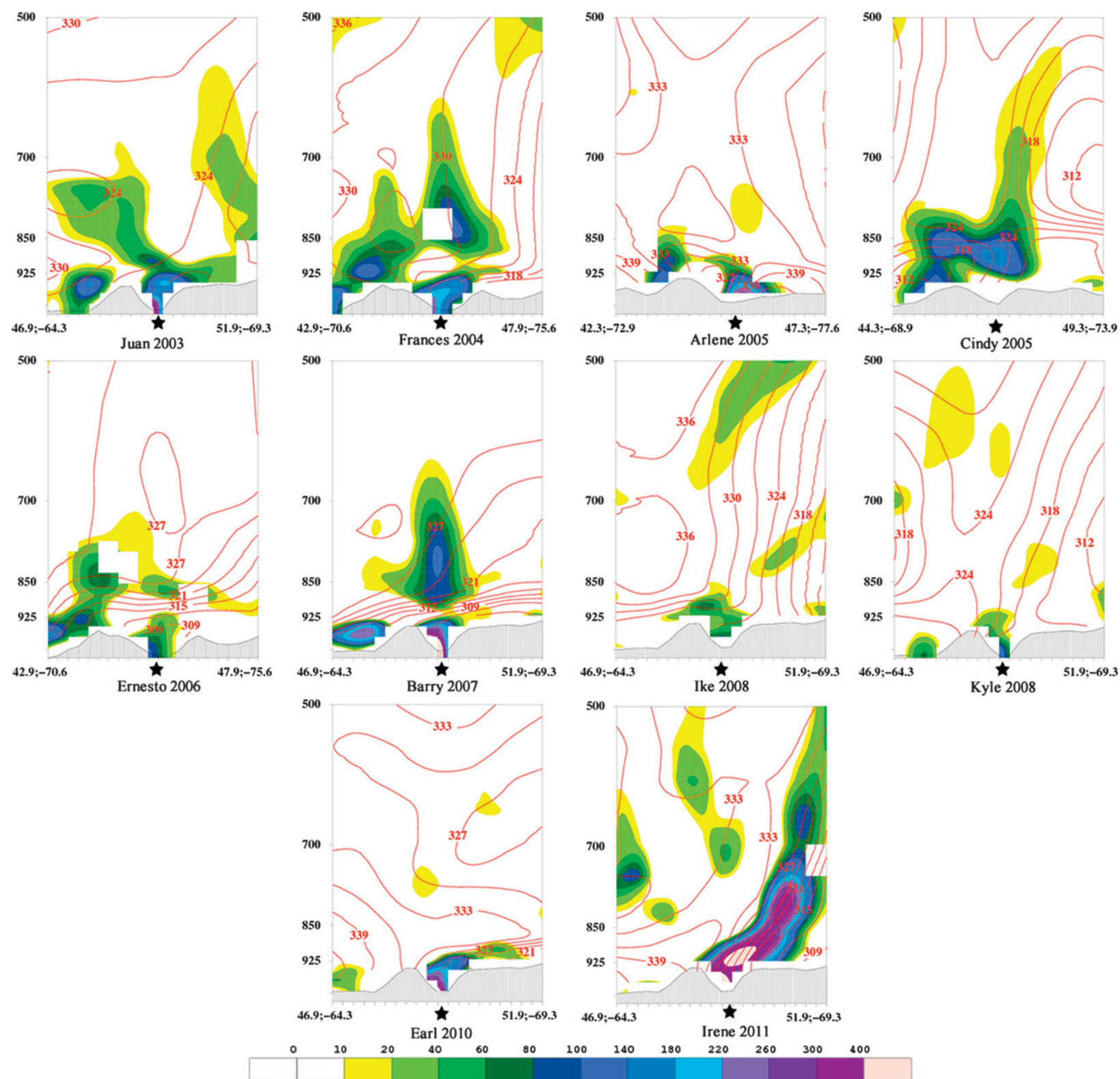

FIG. 12. For the 10 group A cases from 2003 to 2011, cross sections of ageostrophic frontogenesis [shaded, $\times 10^{-2} \mathrm{~K}(100 \mathrm{~km})^{-1}(3 \mathrm{~h})^{-1}$ ] and equivalent potential temperature ( $\mathrm{K}$, red contours), at $t=0 \mathrm{~h}$. The cross-sectional area is denoted by the black lines for each case in Fig. 9. A black star indicates the center of the SLRV in each cross section. The remaining group A cases are available for viewing online (see Supplement 4).

Roebber and Gyakum (2003), Razy et al. (2012), and Ressler et al. (2012) found that northeasterly pressure-driven channeling in the cold season results in cold surface temperatures and strong low-level temperature inversions, which are conducive to freezing rain events in the SLRV. The cold surface temperatures were induced by the channeling of colder surface air from the northeast. The warmer inversion layer was typically located immediately above the surface, and moist neutral profiles were found above the inversion layer (Razy et al. 2012). Figure 13 shows similar results for the transitioning tropical cyclones in group A, despite these events occurring during the warm season. Relatively cold surface temperatures, a lower-tropospheric temperature inversion, and a moist neutral profile above the inversion layer are present in each group A case (Fig. 13). This is consistent with the surface cold potential temperature advection observed in the SLRV (Figs. 6a,b). 

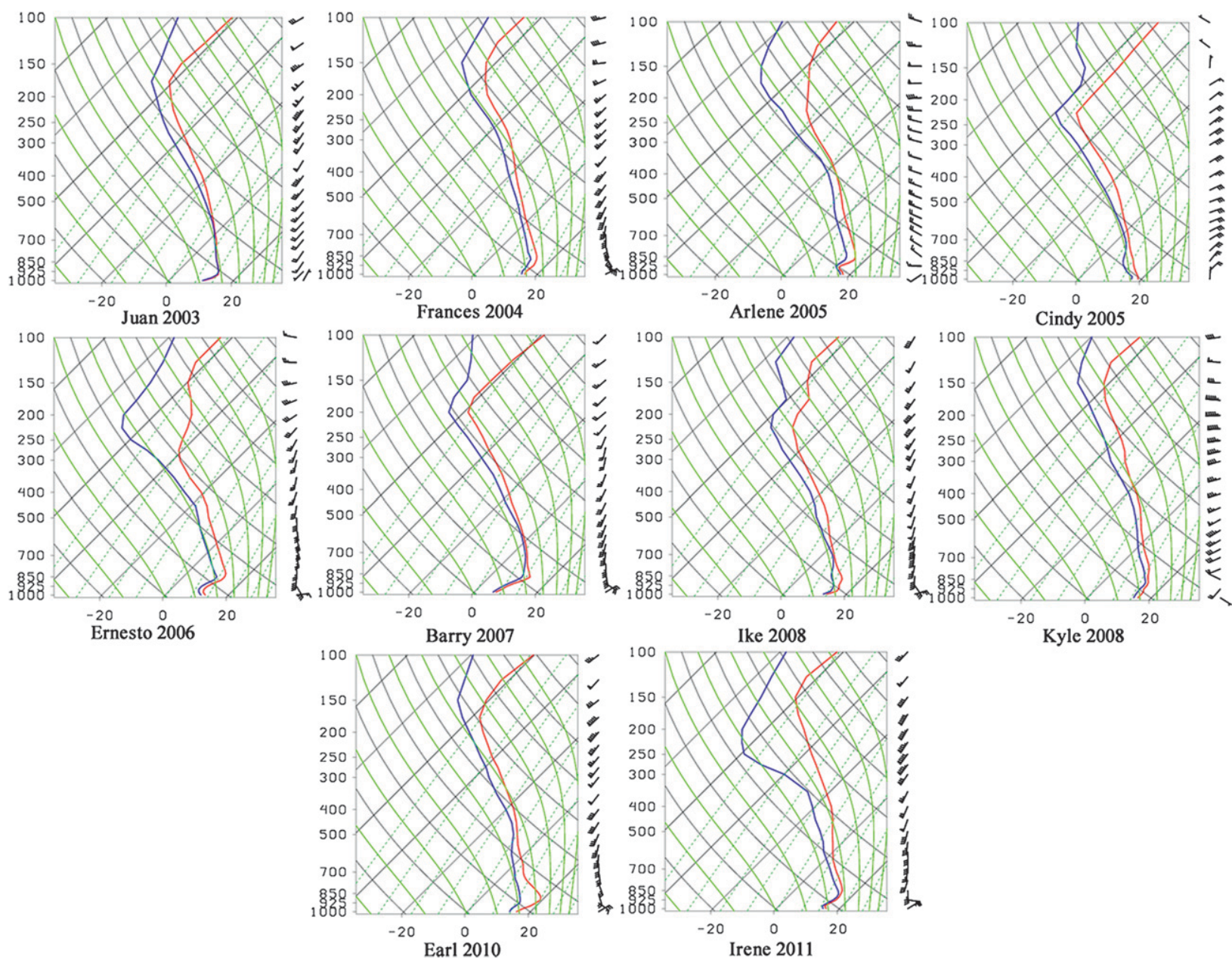

FIG. 13. For the 10 group A cases from 2003 to 2011, NARR soundings at $t=0 \mathrm{~h}$ with temperature $\left({ }^{\circ} \mathrm{C}\right.$, red line), dewpoint $\left({ }^{\circ} \mathrm{C}\right.$, blue line), and winds (kt, barbs). The point chosen for each sounding is marked by a black star in each panel in Fig. 12. The remaining group A cases are available for viewing online (see Supplement 4).

Even in the case of Arlene (2005), where low-level potential instability is evident in Fig. 12, a temperature inversion remains in place above the potentially unstable layer (Fig. 13). Finally, the near-surface winds (Fig. 13) are primarily northeasterly and distinct from winds above the temperature inversions. This is also similar to what Razy et al. (2012) and Ressler et al. (2012) found during cold-season freezing precipitation events.

There are a couple of exceptions to the observation of temperature inversions within group A (e.g., Cindy in 2005, Fig. 13; Karen in 2001; see Supplement 4). In Cindy (2005), convective instability appears to be present in the region of precipitation (Fig. 12). The region of low-level cold potential temperature advection (and thus the temperature inversion) is located to the northeast of the precipitation. For the 10 group A cases for which we have precipitation data, Cindy (2005) is the only exceptional case.

\section{Concluding discussion and future work}

The SLRV is a broad and shallow orographic feature in eastern Ontario and Quebec, Canada (Fig. 1), that has been shown previously to impact surface winds, observed weather, and precipitation distributions during the cold season (Roebber and Gyakum 2003; Razy et al. 2012; Ressler et al. 2012). We examine the impacts of the SLRV orography on precipitation distributions, using 38 cases of transitioning tropical cyclones that tracked within $500 \mathrm{~km}$ of the SLRV (Fig. 3). We find that in 19 of the 38 cases (group A) there is substantial ageostrophic frontogenesis oriented parallel to the long axis of the SLRV (Fig. 4). This low-level, shallow (75-100 hPa) ageostrophic frontogenesis is associated with pressuredriven wind channeling (Roebber and Gyakum 2003; Razy et al. 2012), in addition to a contribution to the ageostrophic frontogenesis from coastal frontogenesis, 


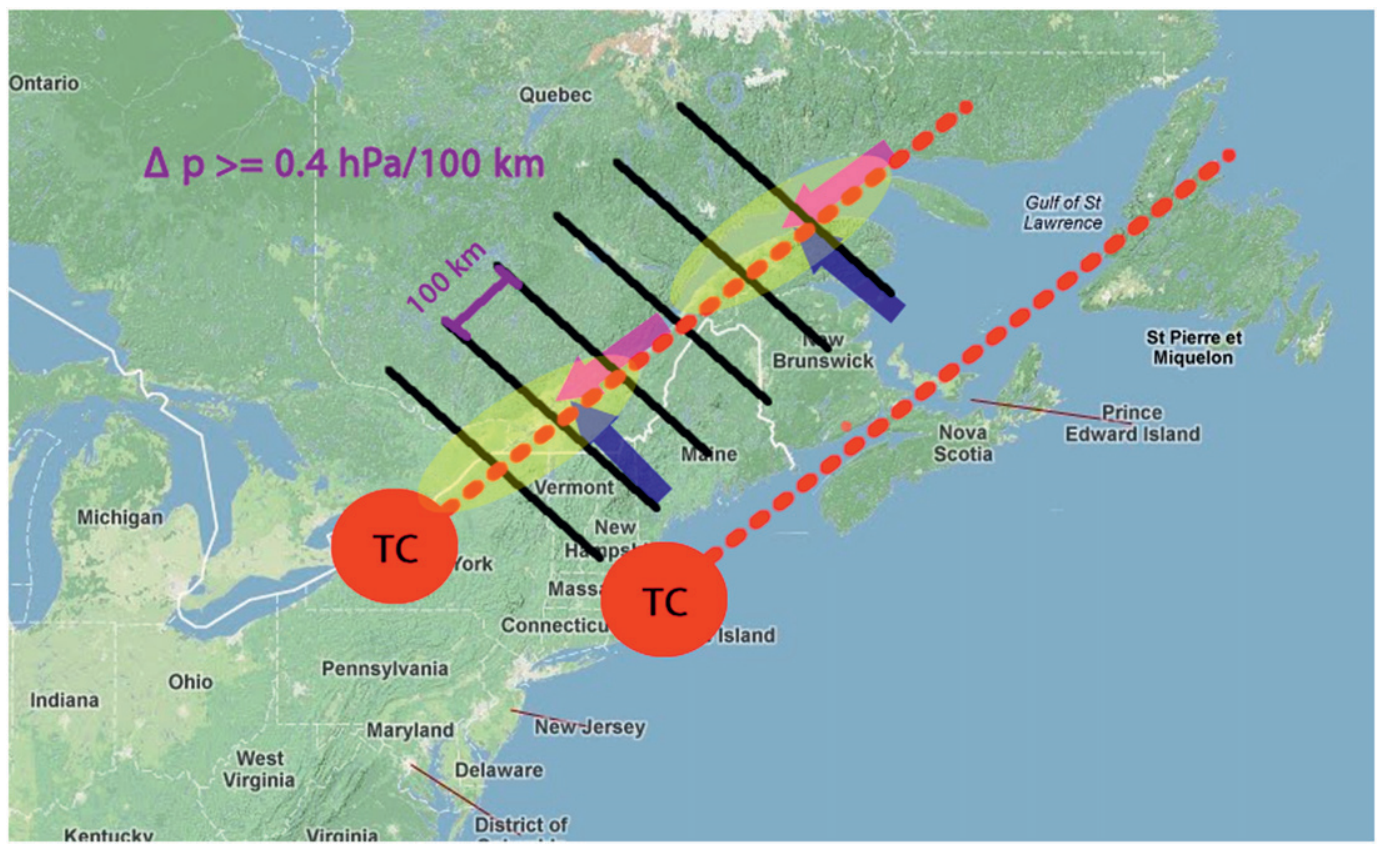

FIG. 14. Schematic showing the processes involved in producing enhanced precipitation in group A cases. The red circles and dotted lines indicate two common storm locations and tracks, respectively, for group A cases. The blue and purple arrows represent the geostrophic and pressure-driven channeled surface wind, respectively. The black lines approximate isobars, with the pressure gradient threshold for pressure-driven channeling identified in Fig. 7 written in purple. The yellow ellipses are typical regions of ageostrophic frontogenesis and precipitation enhancement within the SLRV.

for group A cases in the northeastern SLRV near the Gulf of St. Lawrence. In contrast, group B cases (Fig. 5a) show no substantial ageostrophic frontogenesis in the SLRV and may be associated with forced channeling or downward momentum transport, in which the nearsurface wind direction is similar to the geostrophic wind direction. Moreover, Figs. $6 \mathrm{a}, \mathrm{b}$ and 8 suggest that in group A cases there is near-surface cold-air advection down the SLRV from northeast to southwest, resulting in a low-level temperature inversion (Fig. 13). An analysis of the along-SLRV pressure gradient (Fig. 7) shows that group A cases are associated with larger pressure gradients than group B cases, lending credence to the suggestion of pressure-driven wind channeling.

Although the unreliability of NARR precipitation in Canada limits our assessment of precipitation distribution to 10 group A cases from 2003 to 2011 (Figs. 9 and $10)$, we show that ageostrophic frontogenesis and enhanced precipitation are concomitant and oriented parallel to the SLRV in those cases. A composite analysis of precipitation (Fig. 10) shows that the axis of heaviest precipitation is located within and parallel to the SLRV (Figs. 10b,d), regardless of the location of the center of each cyclone. We acknowledge, however, that Figs. 9 and 10 merely provide circumstantial evidence of the collocation of ageostrophic frontogenesis and enhanced precipitation, and do not conclusively prove that the former is fully responsible for the latter. For example, one can argue that the enhanced precipitation amounts in Ike (2008) line up along a pressure trough-warm front that also happens to be within the SLRV (Fig. 9). Consequently, mesoscale numerical model sensitivity experiments (described below) will be necessary to quantify the impact of the ageostrophic frontogenesis on precipitation amounts.

Figure 11 shows that there is no preference for largescale ascent and geostrophic frontogenesis to be oriented purely within and parallel to the long axis of the SLRV. This suggests that the ageostrophic frontogenesis serves as a mesoscale ascent-focusing mechanism for enhanced precipitation in the SLRV.

In summary, we suggest the following physical pathway to the modulation of heavy precipitation within the SLRV during group A transitioning tropical cyclone events (an associated schematic of this process is presented in Fig. 14):

- A transitioning tropical cyclone approaches the SLRV, and helps to establish a synoptic-scale pressure gradient in the valley, typically pointing from higher 
pressure to the northeast to lower pressure to the southwest (Fig. 14). The pressure gradient within the SLRV generally exceeds $0.4 \mathrm{hPa}(100 \mathrm{~km})^{-1}$ (Figs. 7, 14). This pressure gradient allows for pressure-driven wind channeling from northeast to southwest, resulting in northeasterly surface winds and low-level cold potential temperature advection along the SLRV (Figs. 6a,b, 8, and 14).

- In group A cases, the channeled northeasterly surface winds in the SLRV provide a source of low-level cold air, while surface winds outside of the SLRV are primarily southeasterly (Fig. 14). The ageostrophic frontogenesis in the northeastern SLRV is likely a combination of pressure-driven channeling and coastal frontogenesis driven by the land-SST difference near the Gulf of St. Lawrence (Fig. 8a).

- The ageostrophic frontogenesis induced by pressuredriven channeling (Fig. 14) is shallow (lowest 75-100 mb of the troposphere) and is located primarily within the confines of the SLRV.

- Soundings (Fig. 13) show surface-based cold air, a large low-level temperature inversion, and moist neutral profiles above the inversion layer. As such, we can conclude that the shallow ageostrophic frontogenesis in the SLRV acts as an ascent mechanism that allows air parcels to rise above the inversion layer, to a layer of conditional instability.

In conclusion, this study serves as an assessment of the physical mechanisms responsible for precipitation modulation in the SLRV during transitioning tropical cyclone events. Pressure gradient threshold values for these events have been presented (Fig. 7). In addition, potential temperature, wind, and stability profiles unique to pressure-driven channeling occurrences during these cases have been examined (Figs. 6, 8, 12, and 13). All such findings may be useful to the local forecaster in helping to predict precipitation distributions in the SLRV during the approach of transitioning tropical cyclones.

While the results here do agree with the numerical modeling results of the cold-season study of Roebber and Gyakum (2003), future mesoscale numerical modeling sensitivity studies of our cases are warranted to further corroborate the findings of this paper. Specifically, the amounts of precipitation enhancement due to the orographic effects must be quantified for group A cases. To accomplish this, two mesoscale model simulations should be conducted [similar to the 1998 Ice Storm experiments of Roebber and Gyakum (2003)]: (a) a finescale simulation that accurately replicates the terrain of the SLRV and (b) a coarse-scale simulation in which the terrain in the SLRV region is entirely flat.
Comparisons of precipitation amounts between the two simulations should provide substantial insight into exactly how much the orography of the SLRV (and accompanying pressure-driven channeling) can increase both near-surface ageostrophic frontogenesis and precipitation amounts during transitioning tropical cyclone events.

Acknowledgments. This research has been funded by grants from Ouranos (the regional climate consortium of Quebec), the Natural Sciences and Engineering Research Council of Canada (NSERC), and the Canadian Foundation for Climate and Atmospheric Sciences (CFCAS). Thanks to the National Centers for Environmental Prediction (NCEP) and the National Climatic Data Center (NCDC) for providing access to the NARR, and to Environment Canada and Marco Carrera for providing station precipitation data and access to the Canadian Precipitation Analysis (CaPA), respectively. Finally, thanks to Paul Sisson and John Goff of NWS Burlington, as well as the three anonymous reviewers, for their helpful comments in revising this manuscript.

\section{REFERENCES}

Abraham, J., C. Fogarty, and W. Strapp, 2002: Extratropical transition of Hurricanes Michael and Karen: Storm reconnaissance with the Canadian Convair 580 aircraft. Preprints, 25th Conf. on Hurricanes and Tropical Meteorology, San Diego, CA, Amer. Meteor. Soc., 12D.4. [Available online at http://ams.confex.com/ams/pdfpapers/35168.pdf.]

Amante, C., and B. W. Eakins, 2009: ETOPO1 1 arc-minute global relief model: Procedures, data sources and analysis. NOAA Tech. Memo. NESDIS NGDC-24, 9 pp.

Atallah, E. H., and L. F. Bosart, 2003: The extratropical transition and precipitation distribution of Hurricane Floyd (1999). Mon. Wea. Rev., 131, 1063-1081.

,$- \ldots$, and A. Aiyyer, 2007: Precipitation distribution associated with landfalling tropical cyclones over the eastern United States. Mon. Wea. Rev., 135, 2185-2206.

Becker, E. J., E. H. Berbery, and R. W. Higgins, 2009: Understanding the characteristics of daily precipitation over the United States using the North American Regional Reanalysis. J. Climate, 22, 6268-6286.

Bergstrom, H., and N. Juuso, 2006: A study of valley winds using the MIUU mesoscale model. Wind Energy, 9, 109-129.

Bluestein, H. B., 1992: Principles of Kinematics and Dynamics. Vol. 1, Synoptic-Dynamic Meteorology in Midlatitudes, Oxford University Press, $431 \mathrm{pp}$.

_ 1993: Observations and Theory of Weather Systems. Vol. 2, Synoptic-Dynamic Meteorology in Midlatitudes, Oxford University Press, 585 pp.

Bosart, L. F., 1975: New England coastal frontogenesis. Quart. J. Roy. Meteor. Soc., 101, 957-978.

_, and D. Dean, 1991: The Agnes rainstorm of June 1972: Surface feature evolution culminating in inland storm redevelopment. Wea. Forecasting, 6, 515-536. 
_ - and G. M. Lackmann, 1995: Postlandfall tropical cyclone reintensification in a weakly baroclinic environment: A case study of Hurricane David (September 1979). Mon. Wea. Rev., 123, 3268-3291.

_, C. J. Vaudo, and J. H. Helsdon Jr., 1972: Coastal frontogenesis. J. Appl. Meteor., 11, 1236-1258.

Bukovsky, M. S., and D. J. Karoly, 2007: A brief evaluation of precipitation from the North American Regional Reanalysis. J. Hydrometeor., 8, 837-846.

Canadian Hurricane Centre, cited 2011: Hurricane Ike total precipitation. [Available online at http://www.ec.gc.ca/ouraganshurricanes/.]

Carr, F. H., and L. Bosart, 1978: A diagnostic evaluation of rainfall predictability for Tropical Storm Agnes, June 1972. Mon. Wea. Rev., 106, 363-374.

Carrera, M. L., J. R. Gyakum, and C. A. Lin, 2009: Observational study of wind channeling within the St. Lawrence River valley. J. Appl. Meteor. Climatol., 48, 2341-2361.

Chien, H. H., and P. J. Smith, 1977: Synoptic and kinetic energy analysis of Hurricane Camille (1969) during transit across the southeastern United States. Mon. Wea. Rev., 105, 67-77.

Cohn, S. A., J. R. Gyakum, R. R. Rogers, W. L. Ecklund, D. A. Carter, and J. S. Wilson, 1996: Wind profiler/RASS observations of two complex synoptic events. Beitr. Phys. Atmos., 69, $37-47$.

Colle, B., 2003: Numerical simulations of the extratropical transition of Floyd (1999): Structural evolution and responsible mechanisms for the heavy rainfall over the northeast United States. Mon. Wea. Rev., 131, 2905-2926.

DiMego, G., and L. Bosart, 1982a: The transformation of Tropical Storm Agnes into an extratropical cyclone. Part I: The observed fields and vertical motion computations. Mon. Wea. Rev., 110, 385-411.

$\longrightarrow$, and 1982b: The transformation of Tropical Storm Agnes into an extratropical cyclone. Part II: Moisture, vorticity and kinetic energy budgets. Mon. Wea. Rev., 110, 412-433.

Evans, J., and R. Hart, 2003: Objective indicators of the life cycle evolution of extratropical transition for Atlantic tropical cyclones. Mon. Wea. Rev., 131, 909-925.

Fogarty, C., 2002: Hurricane Michael, 17-20 October 2000: Part ISummary report and storm impact on Canada and Part IIForecast and warning critique. Atlantic Region Science Rep. Series 2002-01, Meteorological Service of Canada, 35 pp. [Available online at http://www.novaweather.net/Hurricane_ Michael_files/Michael_MSC.pdf.]

Google Maps, cited 2011: St. Lawrence River valley. [Available online at http://maps.google.com.]

Gross, G., and F. Wippermann, 1987: Channeling and countercurrent in the Upper Rhine valley: Numerical simulations. J. Climate Appl. Meteor., 26, 1293-1304.

Hart, R., and J. Evans, 2001: A climatology of the extratropical transition of Atlantic tropical cyclones. J. Climate, 14, 547-564.

Hoskins, B. J., I. Draghici, and H. C. Davies, 1978: A new look at the $\omega$-equation. Quart. J. Roy. Meteor. Soc., 104, 31-38.

Jones, S., and Coauthors, 2003: The extratropical transition of tropical cyclones: Forecast challenges, current understanding, and future directions. Wea. Forecasting, 18, 1052-1092.

Keyser, D., M. J. Reeder, and R. J. Reed, 1988: A generalization of Petterssen's frontogenesis function and its relation to the forcing of vertical motion. Mon. Wea. Rev., 116, 762-780.

Koch, S., M. DesJardins, and P. Kocin, 1983: An interactive Barnes objective map analysis scheme for use with satellite and conventional data. J. Climate Appl. Meteor., 22, 1487-1503.
Kossmann, M., and A. P. Sturman, 2003: Pressure-driven channeling effects in bent valleys. J. Appl. Meteor., 42, 151-158.

Ma, S., H. Ritchie, J. Gyakum, J. Abraham, C. Fogarty, and R. McTaggart-Cowan, 2003: A study of the extratropical reintensification of former Hurricane Earl using Canadian Meteorological Centre regional analyses and ensemble forecasts. Mon. Wea. Rev., 131, 1342-1359.

Mahfouf, J. F., B. Brasnett, and S. Gagnon, 2007: A Canadian Precipitation Analysis (CaPA) project: Description and preliminary results. Atmos.-Ocean, 45, 1-17.

Matano, J., 1958: On the synoptic structure of Hurricane Hazel, 1954, over the eastern United States. J. Meteor. Soc. Japan, 36, 23-31.

McTaggart-Cowan, R., J. Gyakum, and M. Yau, 2003: The influence of the downstream state on extratropical transition: Hurricane Earl (1998) case study. Mon. Wea. Rev., 131, 1910-1929.

_ - — , and — 2004: The impact of tropical remnants on extratropical cyclogenesis: Case study of Hurricanes Danielle and Earl (1998). Mon. Wea. Rev., 132, 1933-1951.

— , E. H. Atallah, J. R. Gyakum, and L. F. Bosart, 2006a: Hurricane Juan (2003). Part I: A diagnostic and compositing lifecycle study. Mon. Wea. Rev., 134, 1725-1747.

— L. F. Bosart, J. R. Gyakum, and E. H. Atallah, 2006b: Hurricane Juan (2003). Part II: Forecasting and numerical simulation. Mon. Wea. Rev., 134, 1748-1771.

Mesinger, F., and Coauthors, 2006: North American Regional Reanalysis. Bull. Amer. Meteor. Soc., 87, 343-360.

Miller, J. E., 1948: On the concept of frontogenesis. J. Meteor., 5, 169-171.

Milrad, S. M., E. A. Atallah, and J. R. Gyakum, 2009: Dynamical and precipitation structures of poleward-moving tropical cyclones in eastern Canada, 1979-2005. Mon. Wea. Rev., 137, 836-851.

,-- , and -2010 : Synoptic typing of extreme cool-season precipitation events at St. John's, Newfoundland, 1979-2005. Wea. Forecasting, 25, 562-586.

NCDC, cited 2010: Eastern U.S. flooding and ice storm. [Available online at http://www.ncdc.noaa.gov/oa/reports/janstorm/ janstorm.html.]

Novak, D. R., L. F. Bosart, D. Keyser, and J. S. Waldstreicher, 2004: An observational study of cold season-banded precipitation in northeast U.S. cyclones. Wea. Forecasting, 19, 993-1010.

_ - J. S. Waldstreicher, D. Keyser, and L. F. Bosart, 2006: A forecast strategy for anticipating cold season mesoscale band formation within eastern U.S. cyclones. Wea. Forecasting, 21, 3-23.

Palmén, E., 1958: Vertical circulation and release of kinetic energy during the development of Hurricane Hazel into an extratropical storm. Tellus, 10,1-23.

Powe, N. N., 1969: The climate of Montreal. Climatological Study, No. 15, Meteorology Bureau, Canadian Department of Transport, 51 pp. [Available from Supply and Services Canada, Canadian Government Publishing Centre, Ottawa ON K1A 0S9, Canada.]

Razy, A., 2010: Synoptic analysis of cold-season surface wind regimes in Montreal. M.S. thesis, Dept. of Atmospheric and Oceanic Sciences, McGill University, 102 pp.

_- S. M. Milrad, E. H. Atallah, and J. R. Gyakum, 2012: Synopticscale environments conducive to orographic impacts on coldseason surface wind regimes at Montreal, Quebec. J. Appl. Meteor. Climatol., 51, 598-616.

Ressler, G. M., S. M. Milrad, E. H. Atallah, and J. R. Gyakum, 2012: Synoptic-scale analysis of freezing rain events in Montreal, Quebec. Wea. Forecasting, 27, 362-378. 
Roebber, P. J., and J. R. Gyakum, 2003: Orographic influences on the mesoscale structure of the 1998 ice storm. Mon. Wea. Rev., 131, 27-50.

Rotunno, R., W. C. Skamarock, and C. Snyder, 1994: An analysis of frontogenesis in numerical simulations of baroclinic waves. J. Atmos. Sci., 51, 3373-3398.

Saha, S., and Coauthors, 2010: The NCEP Climate Forecast System Reanalysis. Bull. Amer. Meteor. Soc., 91, 10151057.

Slonosky, V. C., 2003: The meteorological observations of JeanFrancois Gaultier, Quebec, Canada: 1742-56. J. Climate, 16, 2232-2247.
Weber, R. O., and P. Kaufmann, 1998: Relationship of synoptic winds and complex terrain flows during the MISTRAL field experiment. J. Appl. Meteor., 37, 1486-1496.

Weese, S., 2003: A reanalysis of Hurricane Hazel (1954). M.S. thesis, Dept. of Atmospheric and Oceanic Sciences, McGill University, $123 \mathrm{pp}$.

West, G. L., W. J. Steenburgh, and W. Y. Y. Cheng, 2007: Spurious grid-scale precipitation in the North American Regional Reanalysis. Mon. Wea. Rev., 135, 2168-2184.

Whiteman, C. D., and J. C. Doran, 1993: The relationship between overlying synoptic-scale flows and winds within a valley. J. Appl. Meteor., 32, 1669-1682. 